\title{
GEE4FLOOD: rapid mapping of flood areas using temporal Sentinel-1 SAR images with Google Earth Engine cloud platform
}

\author{
Venkata Sai Krishna Vanama, ${ }^{\mathrm{a}, *}$ Dipankar Mandal, ${ }^{\mathrm{b}}$ and \\ Yalamanchili Subrahmanyeswara Rao ${ }^{\mathrm{b}}$ \\ andian Institute of Technology Bombay, Centre for Urban Science and Engineering, \\ Mumbai, Maharashtra, India \\ bIndian Institute of Technology Bombay, Centre of Studies in Resources Engineering, \\ Mumbai, Maharashtra, India
}

\begin{abstract}
The present state of the art technologies for flood mapping are typically tested on small geographical regions due to limitation of resources, which hinders the implementation of real-time flood management activities. We proposed a unified framework (GEE4FLOOD) for rapid flood mapping in Google Earth Engine (GEE) cloud platform. With the unexpected spells of extreme rainfall in August 2018, many parts of Kerala state in India experienced a major disastrous flood. Therefore, we tested the GEE4FLOOD processing chain on August 2018 Kerala flood event. GEE4FLOOD utilizes multitemporal Sentinel-1 synthetic aperture radar images available in GEE catalog and an automatic Otsu's thresholding algorithm for flood mapping. It also utilizes other remote sensing datasets available in GEE catalog for permanent water body mask creation and result validation. The ground truth data collected during the Kerala flood indicates promising accuracy with $82 \%$ overall accuracy and $78.5 \%$ accuracy for flood class alone. In addition, the entire process from data fetching to flood map generation at a varying geographical extent (district to state level) took $\sim 2$ to $4 \mathrm{~min}$. (C) 2020 Society of Photo-Optical Instrumentation Engineers (SPIE) [DOI: 10.1117/1.JRS.14.034505]
\end{abstract}

Keywords: flood mapping; synthetic aperture radar backscatter; Global Precipitation Measurement Integrated Multisatellite Retrievals; Kerala flood; Otsu.

Paper 190885 received Nov. 13, 2019; accepted for publication Jun. 17, 2020; published online Jul. 9, 2020.

\section{Introduction}

Floods are one of the major costliest disasters ${ }^{1-3}$ in the world. Flood information, such as the spatio-temporal location of flooded areas, flood depth, vulnerability, risk localities, and safe zones, are crucial in disaster management response activities. ${ }^{4,5}$ Timely dissemination of flood information to the disaster personnel and civilians can minimize the losses. For the last two decades, the scientific community has advocated the potential of the remotely sensed Earth observation (EO) datasets to provide flood maps in real-time flood monitoring applications. ${ }^{6,7}$ With the availability of new generation EO satellites having improved spatial and temporal coverage, the flood mapping and monitoring capabilities are qualitatively enhanced. ${ }^{8}$ However, with the high data rate of these satellites, the requirements of high-performance computing facilities, such as storage capacity, system software and hardware, internet connectivity, and robust flood mapping algorithms, are necessary. ${ }^{9-11}$

Among different EO datasets, synthetic aperture radar (SAR) is useful for flood mapping due to its all-weather sensing ability. It is preferred over optical remote sensing data because the SAR signals can penetrate through the clouds to sense the Earth objects, which is essential for flood mapping during heavy rainfall and cloud cover. Any disaster events (floods, earthquakes, and cyclones) trigger some changes either in geometric or dielectric or both properties of the sensing objects, which can be efficiently monitored by SAR backscatter. The SAR backscatter from areas

*Address all correspondence to Venkata Sai Krishna Vanama, E-mail: vsaikrishna1990@gmail.com 
submerged under flood water is distinct from nonflooded areas that allow accurate flood mapping possible. ${ }^{12}$ Several studies investigate the efficient use of SAR data in flood mapping. ${ }^{13-16}$ The advantage of multitemporal SAR images over a single SAR image is a reduction in overestimation of the flooded area. ${ }^{17,18}$ In terms of polarization, co-pol data like horizontal transmission and horizontal receive $(\mathrm{HH})$ or vertical transmission and vertical receive (VV) channels are preferred over cross-pol data like horizontal transmission and vertical receive (HV) or vertical transmission and horizontal receive $(\mathrm{VH})$ channels. ${ }^{19}$ Also, the combined use of co-pol and cross-pol images enhance the flood mapping accuracy, especially in urban areas. ${ }^{20}$ Quad-pol data detected $90 \%$ of flood area when compared against optical derived flood maps. ${ }^{21}$

In several studies, with the availability of preflood and flood images, different change detection approaches, such as ratio index ${ }^{22} \log$ ratio, ${ }^{23}$ difference index,${ }^{15,24,25}$ normalized change index,${ }^{26,27}$ and polarimetric difference image, ${ }^{22,28}$ combined with different thresholding algorithms are used to generate the flood maps. In addition to this, machine learning algorithms, such as support vector machine, ${ }^{29}$ artificial neural networks, ${ }^{30}$ fuzzy logic, ${ }^{31-33}$ and object-oriented, ${ }^{34}$ texture-based classification algorithms, are explored in flood mapping. ${ }^{35}$ Probabilistic and deterministic approaches were also investigated and resulted in enhanced accuracy and reliability of flood mapping. ${ }^{36}$

SAR image acquisition at the time of flood peak helps in better understanding the event. Fortunately, many datasets are available in case of the 2007 flood event that occurred in Tewkesbury, United Kingdom, which became a standard experiment site for researchers. The changes due to this flood event at varying spatial scales were analyzed rigorously with simple local threshold and segmentation, ${ }^{37}$ split-window-based automatic thresholding combined with hybrid Markov model,$^{38}$ region growing algorithm along with change detection technique, ${ }^{39}$ and supervised classification approach. ${ }^{40}$ Mason et al. ${ }^{41}$ utilized object-based segmentation and classification algorithms to estimate the flood extent and floodwater levels. Among several techniques, the specular reflective properties of water surface have driven many efforts to determine thresholdbased approaches to identify as a flooded resolution cell in a radar image., ${ }^{6,35,39}$

The thresholding approaches are principally divided into three groups based on manual intervention: automatic, semiautomatic, and manual, ${ }^{42}$ which can be applied at either global or local level. Various thresholding algorithms, such as Otsu's, ${ }^{43}$ Kittler and Illingworth's, ${ }^{44}$ Kapur et al.'s ${ }^{45}$ Tsai's,${ }^{46}$ and active contour thresholding, ${ }^{47,48}$ are explored in several flood mapping studies. ${ }^{49,50}$ An unsupervised fuzzy-based flood area classification uses amplitude and image texture information. ${ }^{33,51}$

However, in most of the above-mentioned research, the implementation of the algorithms was performed on a smaller subset ( 5 to $50 \mathrm{~km}^{2}$ test sites) of the flood-affected region on a local personal computer (PC). In case, if the flood event occurs in a larger spatial extent (approximately thousands of square kilometers), it would be challenging to analyze the images in local PC. The data preprocessing and algorithm implementation in a local PC take a long time due to resources limitations such as storage capacity and processing speed. Also, when the Sentinel-1 SAR datasets are considered, it cannot handle multitemporal images as each single look complex (SLC) image is $\sim 4$ GB of volume. So, dissemination of flood information for the entire flood region is quite challenging with a local PC. Indeed, the use of such high volume datasets for operational flood mapping is far away from being consolidated. Therefore, there is a need to see the applicability of these approaches on large-scale flood events in cloud platform, which enable towards operational flood management. However, the flood area mapping algorithm using SAR data for a large scale is more challenging to design; absolutely automated algorithms that require zero human interference are limited.

German Aerospace Center has developed the Water Suite, which contains four operational approaches for water area extraction from SAR data. Martinis et al. ${ }^{52}$ compared the application of the Water Suite on different test sites using commercial TanDEM-X SAR data. This study suggested that integration of multitemporal SAR images can reduce the misclassification in water surface mapping. Furthermore, the HASARD tool provided research community to detect and monitor near real-time (NRT) flood using SAR images. ${ }^{53}$ It is implemented on the European Space Agency's (ESA) Grid Processing on Demand cloud platform. HASARD tool uses multitemporal Sentinel-1 SAR images, and the background algorithm is developed from a progressively optimized data processing chain for several techniques. ${ }^{54-56}$ However, HASARD does not 
allow the user to modify or fine-tune their algorithm. In summary, the existing cloud processing platforms and operational approaches use limited EO datasets and are not easily accessible to everyone. Therefore, there is a need for cloud processing platform that uses a multitude of EO datasets and also easily accessible to the end users.

In a cloud-based system such as Google Earth Engine (GEE), users can fetch and process high volumes of Sentinel-1 data directly in the cloud, instead of downloading and processing in a local system. ${ }^{57}$ Data processing is performed in parallel on Google's computational infrastructure, which dramatically improves the processing efficiency and open significant opportunities for end users. In recent years, the GEE cloud platform is widely used in numerous remote sensing applications. ${ }^{58,59}$ Several studies use time-series EO data available in GEE catalog for many operational applications, such as urban growth mapping, ${ }^{60-62}$ global forest change ${ }^{63}$ global forest watch, ${ }^{63,64}$ and global surface water explorer. ${ }^{65}$ In a very recent study, Uddin et al. ${ }^{66}$ utilized the GEE and Sentinel datasets to analyze the 2017 flood event in Bangladesh by generating the land use land cover map required for flood area validation. Other studies show the efficient way of handling a large volume of multitemporal EO data available in GEE cloud

platform. ${ }^{62,67,68}$ From these studies, it is inferred that GEE platform has many advantages, such as availability of multitemporal EO datasets, parallel processing architecture, and is efficient in handling big datasets. All the above-mentioned facts suggest that the cloud-based rapid flood mapping system needs to be freely available, efficient, accurate, and user-friendly to stakeholders and decision-makers.

In this study, we propose a unified framework (named as GEE4FLOOD) for rapid flood mapping using Sentinel-1 SAR images through a processing chain in GEE cloud platform. The GEE4FLOOD is efficient in handling big data, easy to implement with minimal user inputs, effective processing time and scalable to larger spatial extent flood mapping, and universally applicable. In this paper, GEE4FLOOD is tested on August 2018 major flood event of Kerala state, India. For thresholding SAR images in GEE, an automatic Otsu's thresholding algorithm is used. Finally, we exploit Sentinel-1 SAR images to produce operational highresolution flood maps over a larger spatial extent. The rest of this paper is organized as follows. Section 2 describes the study area and details of Kerala flood event and its impact. The research methodology adopted for the study is explained in Sec. 3. In Sec. 4, results and discussions are presented. The conclusions of the study are summarized in Sec. 5.

\section{Study Area and Datasets}

\subsection{Study Area}

This study focuses on the significant flood event that occurred in Kerala, a southern state of India, during August 2018, as shown in Fig. 1. Kerala is situated between $8.291^{\circ} \mathrm{N}$ to $12.795^{\circ} \mathrm{N}$ latitudes and $74.863^{\circ} \mathrm{E}$ to $77.412^{\circ} \mathrm{E}$ longitudes. The spatial extent of the Kerala state is about $38,863 \mathrm{~km}^{2}$. The state is majorly categorized into three geographical regions, i.e., low lands, mid lands, and high lands. Low lands are mainly characterized by backwaters, river deltas, and Arabian Sea shore. ${ }^{69}$ Unlike other metropolitan cities, the urban areas in Kerala state are covered with a large amount of tree cover.

Kerala state received two abnormal rainfall spells during August 7 to 9, 2018, and August 14 to 19,2018 . A total of $857.4 \mathrm{~mm}$ of rainfall, which is $18 \%$ above normal, occurred in July 2018. It is the first onset of flooding in Kerala state. With this heavy rainfall in July 2018, the rainwater started flowing into the dams. Later, the state received a total rainfall of $758.6 \mathrm{~mm}$ between August 1, 2018, and the end of second rainfall spell, which is $164 \%$ more than normal rainfall. ${ }^{70}$ By the end of the first rainfall spell, the water level in several dams was up to full reservoir level. The water from the dams was released due to heavy rainfall at the time of second rainfall spell. Also, there were numerous landslides throughout the Kerala state. This unprecedented massive rainfall combined with dam water release, ${ }^{71}$ landslides, and improper urban planning contributed to severe flooding in 13 out of 14 districts in Kerala state. According to the National Disaster Management Authority, Kerala State Disaster Management Authority (KSDMA), and other secondary sources, a large part of Kerala's population is affected by 


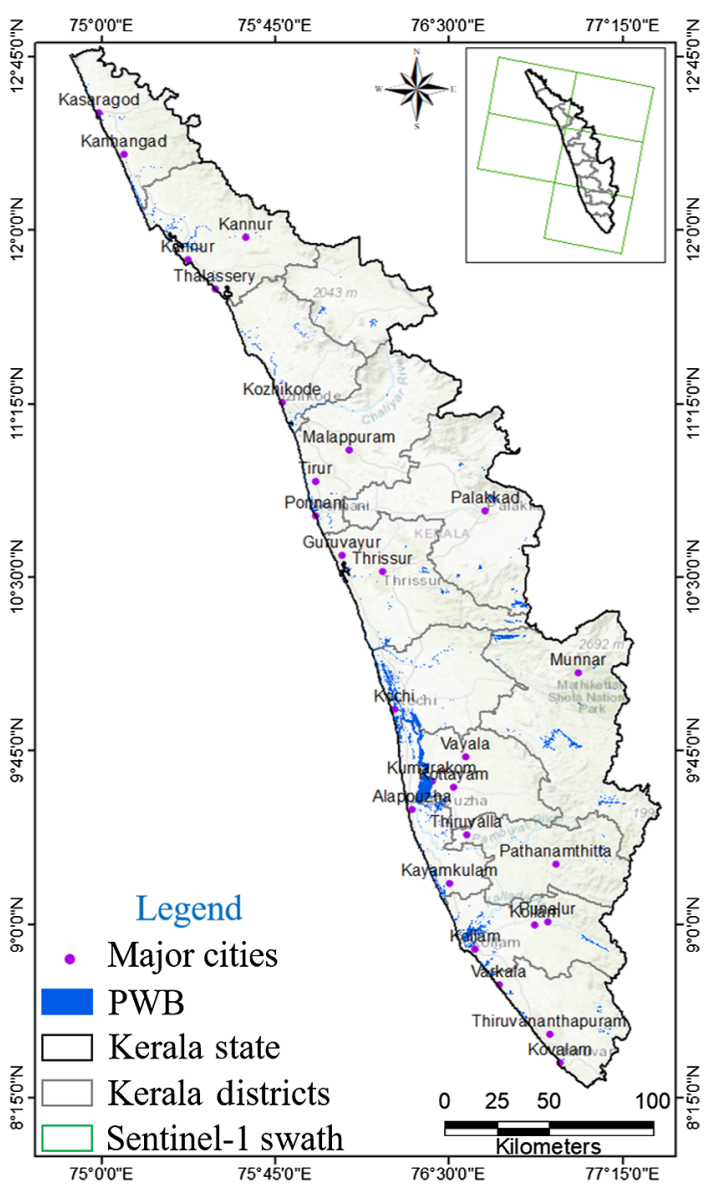

Fig. 1 Study area showing the Kerala state of India. Sentinel-1 swath coverage over the test area is shown in green rectangles. PWB is derived from GEE and the details are explained in Sec. 3.3.

floods and its related vector-borne diseases. According to KSDMA, 504 people died, and 3.4 million people were accommodated in 12,300 relief camps. The other socio-economic losses include damage to houses (10,319 complete damaged and 100,000 partially damaged), damage to $10,000 \mathrm{~km}$ of transport network, and $600 \mathrm{~km}^{2}$ of agriculture crops. ${ }^{72}$ All these facts about Kerala flood prove that there is an immense requirement of flood maps, which can help in postdisaster management activities and resilient disaster planning.

\subsection{Datasets}

For mapping the spatial extent of 2018 Kerala flood event, both SAR and optical images are used. The Sentinel-1 SAR images that are available before, during, and after the flood are used. The Sentinel-1 Ground Range Detected (GRD) images obtained from GEE platform are already preprocessed $^{73}$ to terrain-corrected $\sigma^{0}$ images with a pixel size of $10 \times 10 \mathrm{~m}$. As the Sentinel-1 orbital information is accurate, the terrain-corrected SAR images also have subpixel geolocation accuracy. The specification of the SAR images used in the research is given in Table 1. To validate the results, WorldView-3 optical images that are freely available from DigitalGlobe under open data program, ${ }^{74}$ Sentinel-2, and Landsat- 8 optical images are used. The WorldView-3 image acquired before the flood, i.e., on March 9, 2018, was only used to understand the land use pattern of the study area. Also, the field data collected during and after the flood are used for validation. The spatial resolution of WorldView-3, Sentinel-2, and Landsat-8 optical images is $0.5 \mathrm{~m}, 10 \mathrm{~m}$, and $30 \mathrm{~m}$, respectively.

Apart from these imaging satellite datasets, the Global Precipitation Measurement (GPM) precipitation data, i.e., Integrated Multisatellite Retrievals for GPM (IMERG), and World Wildlife Fund (WWF) HydroSHEDS flow accumulation data are fetched into the GEE platform 
Table 1 Sentinel-1 images fetched from GEE for 2018 Kerala flood mapping.

\begin{tabular}{lccc}
\hline \hline Date of acquisition & Polarization & Pass & Flood condition \\
\hline January 05, 2018 & VV & Des & Preflood \\
July 16, 2018 & VV & Des & Flood \\
July 28, 2018 & VV & Des & Flood \\
August 9, 2018 & VV & Des & Flood \\
August 21, 2018 & VV & Des & Flood \\
August 27, 2018 & VV & Des & Flood \\
September 2, 2018 & VV & Des & Postflood \\
\hline \hline
\end{tabular}

for further understanding of flooding pattern in the state. The spatial resolutions of IMERG precipitation and flow accumulation layers are $0.1 \mathrm{deg}$ and 15 arc sec, respectively, and the detailed description of these datasets are given in Earth Engine Data Catalog. ${ }^{75}$

\section{Methodology}

GEE cloud platform can execute multiple tasks impeccably from data fetching to flood mapping in a holistic approach as it works on a parallel processing architecture. Several steps in the flood mapping processing chain are divided into four modules, i.e., (1) Sentinel-1 data fetching, (2) metadata filtering in GEE cloud platform, (3) creation of permanent water body (PWB) mask, and (4) rapid flood mapping through an automated systematic procedure. The conceptual framework of the proposed processing chain for rapid flood mapping using Sentinel-1 with GEE is shown in Fig. 2.

\subsection{Sentinel-1 Data Fetching}

GEE data catalog provides a wide range of remote sensing datasets, such as optical, thermal, infrared, and microwave images. In this work, the readily available level-2 processed high-resolution GRD Sentinel-1 images are utilized. A massive volume of 264 time-series

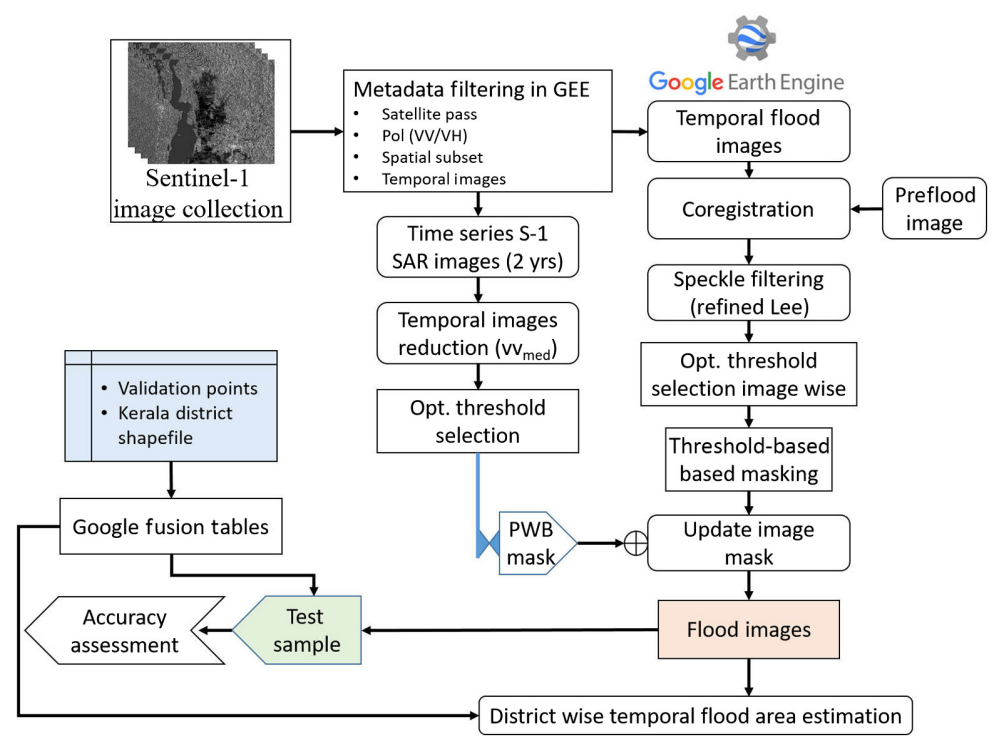

Fig. 2 Schematic workflow for rapid flood mapping in GEE cloud platform. 
Sentinel-1 images, which are available between January 1, 2015, to December 31, 2017, with a revisit time of 12 days interval are used for PWB mask creation. A total of seven Sentinel-1 images (Table 1) that are available at preflood, flood, and postflood time duration are used for Kerala flood mapping. All these images are directly fetched from GEE data catalog to GEE processing platform using Earth Engine operator (ee.ImageCollection) as an image collection. As the Sentinel-1 images available on GEE are already preprocessed to terrain-corrected radar backscatter $\sigma^{0}$, the time required in data downloading, SLC to GRD conversion, and data preprocessing time is saved in GEE cloud platform.

\subsection{Metadata Filtering}

The Sentinel-1 image collection fetched from the previous step posses enormous information about each image. The metadata information, such as data acquisition mode, acquisition time, satellite pass, polarization, incident angle, and orbit number, is stored with image collection. Thus, the user can create a filter to restrict the data volume according to the objective of the work. In this work, all the Sentinel-1 images are filtered with descending pass, Interferometric Wide swath mode, and VV polarization parameters using .filterMetadata operator. Also, the filterDate operator is used to fetch the images according to the image acquisition date. Subsequently, a spatial filter is also created using .filterBounds operator to limit the processing extent within the minimum bounding box of the study area. Thus metadata and spatial filtering play a crucial role in restricting the data volume and processing time.

\subsection{Permanent Water Body Mask Creation}

The PWB mask used in the study was created using two datasets namely, (1) global surface water mapping (GSWM) layer with a spatial resolution of $30 \mathrm{~m}$ and (2) temporal mean SAR image with a pixel size of $10 \mathrm{~m}$. The water occurrence band available with GSWM layer was prepared by Joint Research Centre using time-series Landsat optical images from 1984 to 2015 . A threshold of $>80$ on water occurrence band was considered to obtained optical-based PWB. This indicates where surface water was present at $80 \%$ occurrence over 32 years ${ }^{65}$ capturing interannual and intra-annual changes and variability. However, optical-based PWB has few limitations such as cloud cover and spatial resolution $(30 \mathrm{~m})$. Also, the water bodies may be expanded during monsoon season due to high inflow of rainwater and even change their course in due time after 2015. Therefore, the optical-based PWB mask needs to be updated for accounting seasonality change of water bodies after 2015, with the images acquired after 2015.

To update the optical-based PWB mask, all the 264 Sentinel-1 images are reduced to generate a single mean SAR image using .reduce operator. Several region of interests (ROIs) over water bodies are created in GEE platform that is spatially covering throughout the study area. An automatic Otsu's thresholding algorithm is implemented on the mean SAR image in which water ROIs are used to find an optimum threshold. The SAR-based PWB mask is created in GEE platform by classifying the mean SAR image with all the pixels less than the optimum threshold.

Some water bodies that are not detected by optical remote sensing images are identified by SAR images due to its high sensitivity to dielectric constant. ${ }^{76,77}$ Finally, the optical PWB mask is updated with SAR-based PWB mask to obtain the final PWB mask in GEE platform using .updateMask operator. The GEE .updateMask operator resamples the optical-based PWB to $10 \mathrm{~m}$ and merges with SAR-based PWB mask.

\subsection{Rapid Flood Mapping}

The constellation of Sentinel 1A and 1B satellites can cover the globe with a revisit time of 3 to 12 days depending on the location and ESA program. For the southern part of India, the Sentinel-1 SAR images are acquired for every 12 days in most cases. During the disasters, the images may be acquired with even low revisit time ( 6 days) from both ascending and descending pass directions. There is a time difference between the SAR image acquisition time and ingestion time into GEE catalog. At present, this latency time varies from 30 to $70 \mathrm{~h}$. The GEE developers have plans to reduce this latency time in coming future. ${ }^{78}$ The SAR image ingestion latency time is 
not considered into GEE4FLOOD processing chain time. Therefore, the processing chain is named as rapid flood mapping rather than real-time or NRT flood mapping because of following points.

- Image processing is quite faster in GEE as it runs on parallel processing architecture.

- GEE is efficient in handling massive volume of images.

- GEE is capable of rapid sharing and dissemination (excluding image ingestion latency time) of information at the time of disasters.

The workflow of rapid flood mapping is divided into four submodules, i.e., coregistration, speckle filtering, optimum threshold identification, and flood mapping. Based on the flood duration, the images are grouped as preflood, flood, and postflood images. Among the seven Sentinel-1 images used to understand the flood increasing and decreasing pattern, the images acquired on January 5, 2018, and September 2, 2018, are referred to as preflood and postflood images, respectively. The images acquired between July 15, 2018, and August 28, 2018, are designated as flood images.

For any change detection study, coregistration of master and slave images must be implemented to ensure proper spatial alignment of images. The master image has to be carefully chosen from archived images based on the parameters that influence the radar backscatter $\left(\sigma^{0}\right)$, such as the same satellite track, and atmospheric conditions. Here, the preflood image is treated as the master image since it is acquired on the clear sky, which is free from clouds and with the same satellite track of slave images. The other six sentinel-1 SAR images are treated as slave images.

As the first step of rapid flood mapping procedure, the slave images are precisely coregistered to a preflood image by local rubber sheet deformations in GEE platform using .register operator. Then, the coregistered flood and postflood $\sigma^{0}$ images are converted to natural scale from decibel (dB) scale. A user-defined function is created for refined Lee speckle filter with a $3 \times 3$ window size. Subsequently, to reduce the inherent speckle noise in the SAR data, a refined Lee speckle filter is applied on coregistered flood and postflood images in GEE platform. After speckle filtering, the $\sigma^{0}$ images are converted back to $\mathrm{dB}$ scale. An Otsu's automatic thresholding algorithm is implemented on the speckle filtered images. The detailed explanation is given in Sec. 4.1. The criterion function required for optimal threshold identification is the minimization of within-class variance of the nonflood and flood class pixels in the SAR image. It is the same as maximizing the between-class variance as given in Eq. (1):

$$
\sigma_{B}^{2}=\omega_{f} \omega_{\mathrm{nf}}\left(\mu_{f}-\mu_{\mathrm{nf}}\right),
$$

where $\sigma_{B}^{2}$ is the between-class variance, $\omega_{f}$ and $\omega_{\mathrm{nf}}$ are fraction of flood and nonflood pixels, respectively, and $\mu_{f}$ and $\mu_{\mathrm{nf}}$ are mean values of flood and nonflood pixel classes, respectively. An optimum threshold is identified for each image, and all the pixel values that are less than the threshold are classified as flooded areas. The computational time and memory usage taken for each GEE operator in generating the flood maps along with the description are given in the Appendix in Sec. 6.

\subsection{Validation Approach}

The Kerala flood event happened at a regional level, which covers a larger spatial area. Thus, it is extremely challenging to collect the validation data throughout the entire state as it requires enormous resources. Therefore, the validation is conducted by both direct (field data) and indirect (secondary data) methods.

Secondary data include optical remote sensing images (Landsat-8 and Sentinel-2), 3-h GPM v5 IMERG rainfall data, WWF HydroSHEDs flow accumulation, and hydrologically conditioned digital elevation model (DEM) that are available in GEE catalog have been used in the study. A function is created in GEE platform to generate the daily rainfall by summation of hourly data. All these secondary data are clipped to the required geographical extent in GEE. 
The field data were collected at various locations that are highly affected by flood on different time scales. A narrative survey was conducted during and immediately after the Kerala flood that recorded information such as location, flood depth, and photographs. Also, some photographs were obtained through online sources. ${ }^{79}$ Thus, with the limited field data, validation of the results is confined to region C of Fig. 3. With the help of photographs and survey data, a ground truth flood area polygon vector file was digitized in GEE platform to compare against the results. Various performance indices were defined as follows to find the overall accuracy. The detailed validation approach is given in Sec. 4.3.

- True positive (TP): Number of flood pixels in the ground truth data detected as flood by the algorithm.

- True negative (TN): Number of nonflood pixels in the ground truth data detected as nonflood by the algorithm.

- False positive (FP): Number of nonflood pixels in the ground truth data detected as flood by the algorithm.

- False negative (FN): Number of flood pixels in the ground truth data detected as nonflood by the algorithm.

- True positive rate (TPR): It signifies the proportion of actual flood pixels on the land surface that is correctly detected as such. TPR is computed as TP/(TP + FN), and a high TPR value indicates a better accuracy.

- True negative rate (TNR): It signifies the proportion of actual nonflood pixels on the land surface that is correctly detected as such, and it is computed as TN/(FP + TN).

- Positive predictive value (PPV): It signifies the proportion of flood pixels detected by the algorithm that is actually flooded, which is computed as TP/(TP + FP).

- Negative predictive value (NPV): It signifies the proportion of nonflood pixels detected by the algorithm that is actually nonflooded, and it is computed as TN/(FN + TN).

- Accuracy: It is a measure of how the algorithm correctly identifies either flood or nonflood pixels. It is the proportion of both TP and TN to total number of cases and computed as $(\mathrm{TP}+\mathrm{TN}) /(\mathrm{TP}+\mathrm{FP}+\mathrm{TN}+\mathrm{FN})$.

- $F$-score: A single measure for algorithm performance for flood class pixels alone. It is the harmonic mean of TPR and PPV and computed as per Eq. (2).

$$
F=2 \times \frac{\mathrm{TPR} \times \mathrm{PPV}}{\mathrm{TPR}+\mathrm{PPV}}
$$

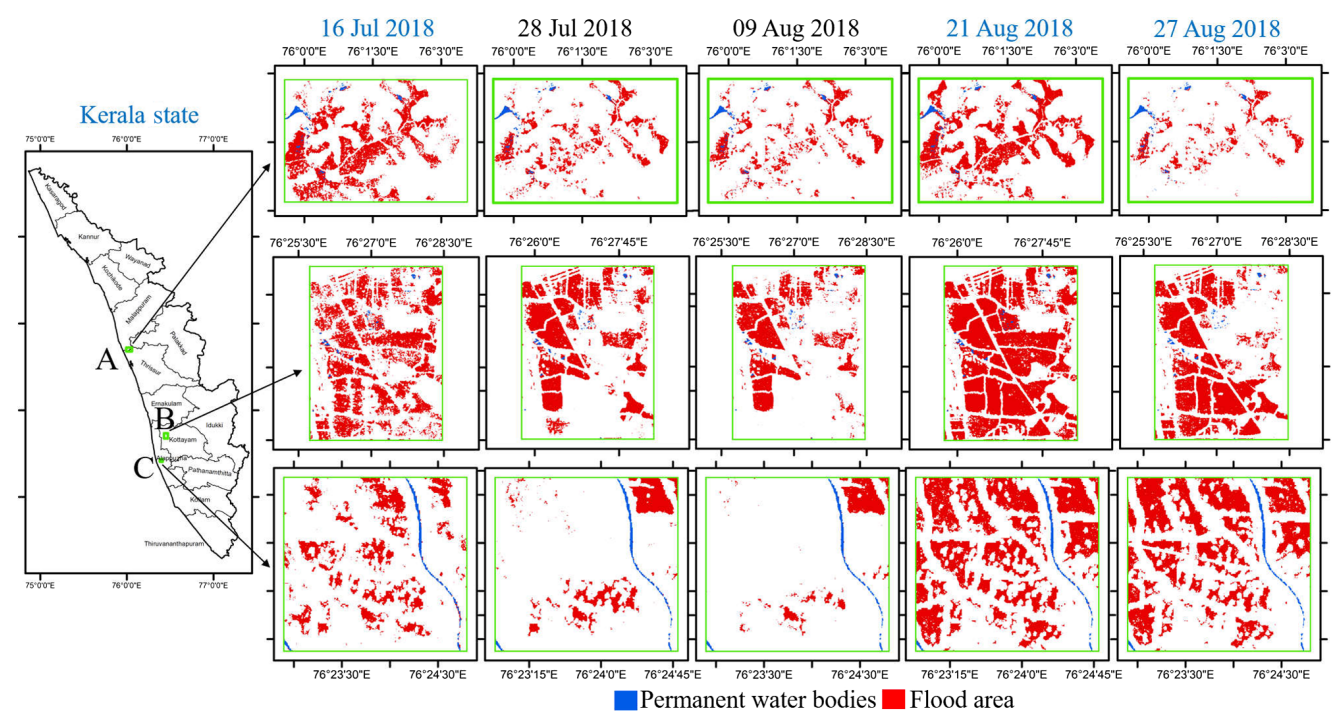

Fig. 3 Spatio-temporal flood maps derived from GEE on July 16, 28, August 9, 21, and 27, 2018, for three regions $A, B$, and $C$ as highlighted on the Kerala state. 


\section{Results and Discussions}

\subsection{Threshold Identification}

A function is developed in GEE platform for Otsu's thresholding algorithm as described in Ref. 43. From the water ROIs, the histograms are obtained as shown in Fig. 4 for all the SAR images that were given as the inputs to the Otsu's function. In each plot of Fig. 4, the speckle filtered backscattered values (orange color histogram) are plotted against the nonfiltered values (blue color histogram). From Fig. 4(a), it is inferred that a bimodal histogram with the values ranging from -4 to $-26 \mathrm{~dB}$ is seen for the preflood image. The lower values $(-18$ to $-26 \mathrm{~dB})$ and higher values $(-14$ to $-4 \mathrm{~dB})$ of the histogram correspond to backscattering from the stable/calm water bodies and dry riverbed/dry sand, respectively. Subsequently, after the first heavy rainfall occurred in July 2018 , the backscatter values started shifting toward the lower values of the histogram, as shown in Fig. 4(b). Here, the histogram is a left-skewed histogram rather than bimodal. This is due to the change of land surface condition from dry to wet and the movement of floodwater to the low elevated areas. From the visual interpretation of three optical images in the first row of Fig. 5, it is evident that the land surface condition is dry at the time of preflood image acquisition and persisted as wet surface even after the July 16, 2018, SAR image acquisition.

In Figs. 4(c) and 4(d), the histograms are shifted toward left with the majority of the values in the range of -24 to $-18 \mathrm{~dB}$. At this phase, the land surface condition is saturated, and the floodwater receded through the drainage channels. Even though the Sentinel-2 optical images acquired on July 28, 2018, and August 7, 2018, as shown in Fig. 5 are partially cloudy,
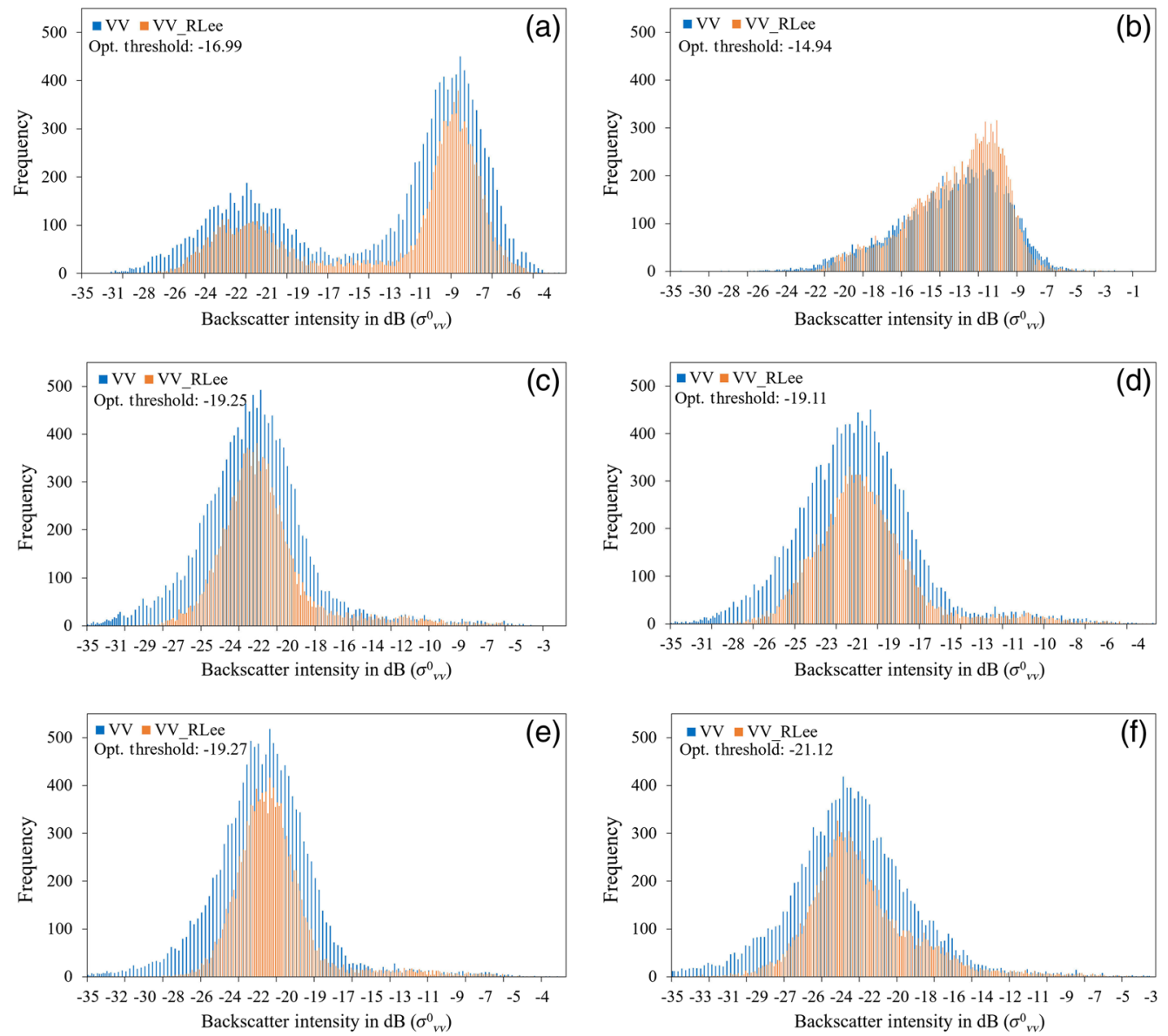

Fig. 4 Temporal histograms of $\sigma_{\mathrm{vv}}^{0}$ before and after speckle filtering of the images acquired on (a) January 5, (b) July 16, (c) July 28, (d) August 9, (e) August 21, and (f) August 27, 2018. 
Vanama, Mandal and Rao: GEE4FLOOD: rapid mapping of flood areas...
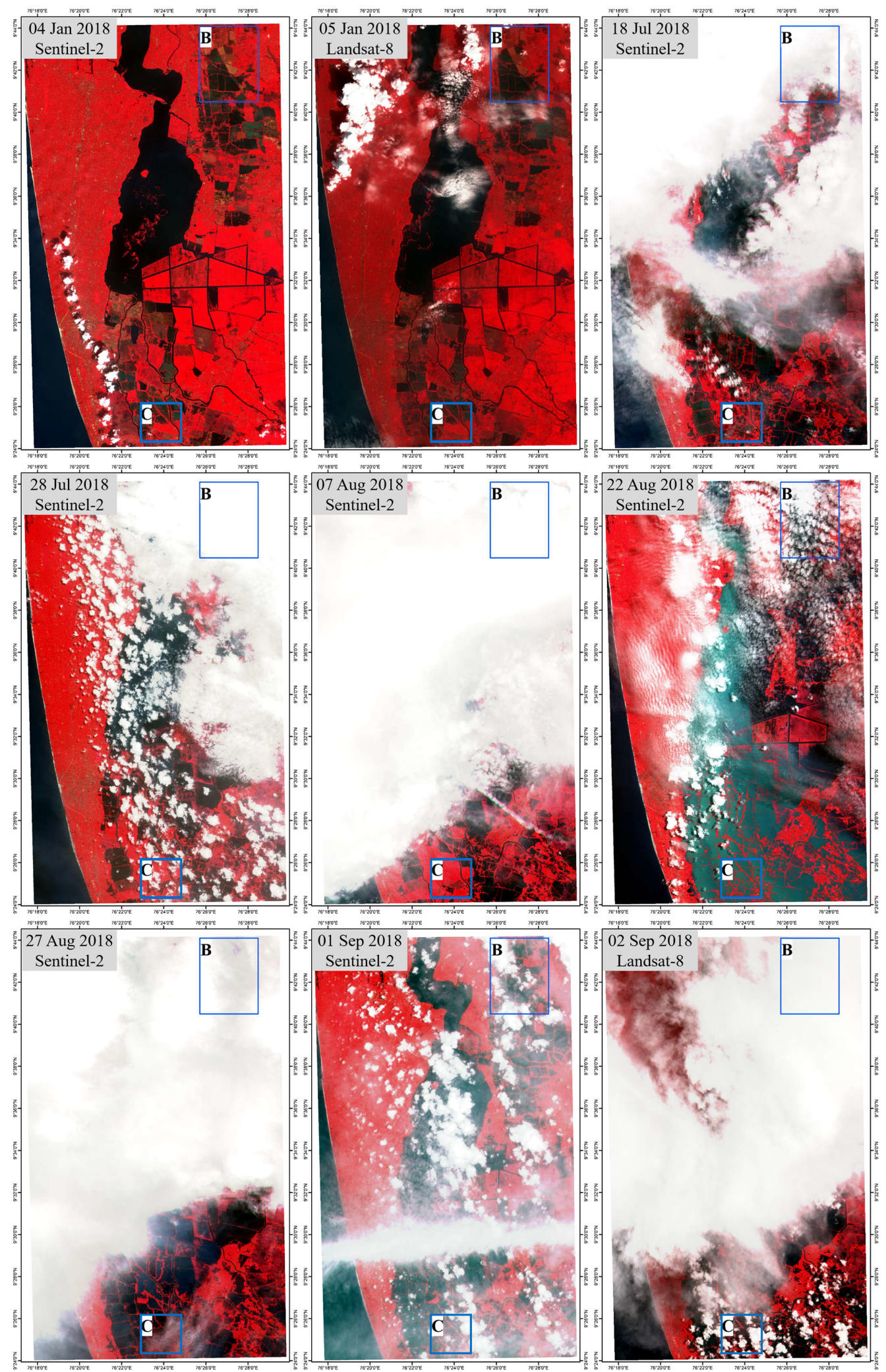

Fig. 5 Optical images acquired within the time duration (before/after) for every corresponding SAR image acquisition. $\mathrm{B}$ and $\mathrm{C}$ are the same regions given in Fig. 3. 
it is understood that agriculture fields in the low lying areas are affected by floodwater. In Fig. 4(e), all the values in the histogram are concentrated around $-22 \mathrm{~dB}$. This is due to a major rainfall spell that occurred during the August 14, 2018, to August 17, 2018, where the land surface got flooded and yielded low backscattering values. This is evident from the visual interpretation of optical images acquired on August 22, 2018, which is a day after the SAR image acquisition on August 21, 2018. In Fig. 4(f), the histogram is right skewed due to high backscattering values as the land surface is started to regain its original condition.

After generating the histograms of all the SAR images, optimum threshold values are obtained by implementing the Otsu's function. The thresholds values obtained for temporal SAR images as shown in Table 1 are $-16.99,-14.94,-19.25,-19.11,-19.27,-21.12$, and $-21.12 \mathrm{~dB}$. However, there are some limitations with Otsu's algorithm. ${ }^{43,80}$ Those limitations include (1) the histogram needs to be bimodal; (2) size of flood and nonflood classes should be comparable; and (3) if the variances of flood and nonflood classes are larger than mean values of flood and nonflood classes, there is possibility of identifying an incorrect threshold. Therefore, due to these limitations, the threshold identified for the temporal images might yield underestimation of flood area. The overestimation of flood area is an extreme low possibility due to masking of water-like reflecting surfaces, such as layover, shadows, fore-shorting regions, and wet lands using preflood image.

\subsection{Spatio-Temporal Flood Mapping}

The initial flood extent is obtained by considering the pixels whose values are lower than the optimum thresholds. The initial flood extent obtained from flood images and postflood images includes flood area along with water bodies and radar-like reflecting surfaces, such as highways and airport runways. The inclusion of water bodies in the flood area identification contributes to overestimation. Therefore, the PWB are masked out using PWB mask in GEE platform to reduce the overestimation. Apart from this, the radar-like reflecting surfaces and wetlands that are detected as flood area in the preflood image are masked out to obtain final flood extent. For a detailed understanding, three regions were selected based on the flood severity, location accessibility, and land use. The spatio-temporal flood extent of these regions A, B, and C are shown in Fig. 3, where red and blue color represent the flood area and PWB, respectively. The processed GPM daily rainfall data obtained in GEE cloud are clipped to the three regions $\mathrm{A}, \mathrm{B}$, and $\mathrm{C}$ in Fig. 3 separately and spatially averaged to get a single value. The quantitative estimation of flood area for the respective regions, as shown in Fig. 3, is plotted against the GPM daily rainfall obtained from GEE, as shown in Fig. 6.

From Fig. 6, it is inferred that the flood area obtained from temporal SAR images follows the rainfall pattern obtained from GPM IMERG data. For example, after the major rainfall spell from August 14 to 19, 2018, the massive runoff generated from rainfall started receding. The same decreasing pattern is also observed in the flood area obtained from temporal SAR images acquired after the major rainfall spell. For the small geographical extent, as shown in Fig. 3, the total time consumed for spatio-temporal flood maps generation is $\sim 1 \mathrm{~min}$. The geographical area of region A in Fig. 3 is $33.62 \mathrm{~km}^{2}$, which is characterized by water bodies, semiurban areas mixed up with tree cover, and agricultural land uses. The geographical area of region B in Fig. 3 is $33.63 \mathrm{~km}^{2}$, which is mainly characterized by agricultural land use and a small portion of semiurban land use. The geographical area of region C in Fig. 3 is $11.78 \mathrm{~km}^{2}$, which is characterized by water bodies, urban areas, open spaces, and agricultural land uses, as shown in Fig. 7. These land features provide unique scattering phenomena when radar electromagnetic wave interactions with the targets are considered. Water has a high dielectric constant and acts as a specular reflector, which yield very low backscatter power return to the sensor. It makes the water bodies to appear as a dark feature in a SAR image (irrespective of polarization channel). For majority of other natural land features, particularly over agricultural areas, the radar wave produces diffused scattering. However, the dominant scattering of radar wave changes with respect to different crop growth stages. In the case of semiurban areas, double-bounce scattering becomes dominant, which is likely due to corner reflection from buildings and the structure of surrounding coconut trees in the study area. 
Vanama, Mandal and Rao: GEE4FLOOD: rapid mapping of flood areas...

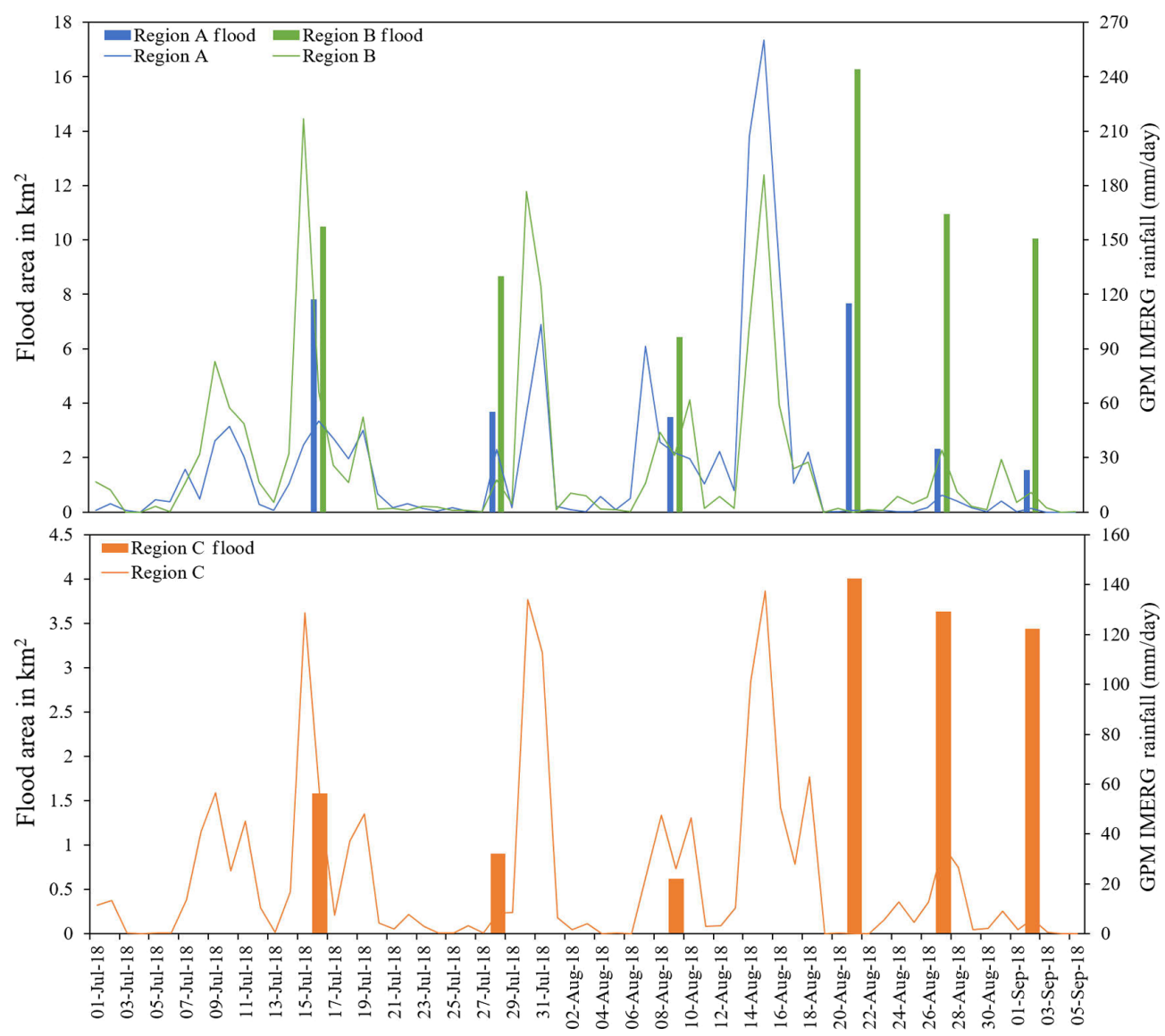

Fig. 6 Flood area obtained from three regions A, B, and C, as shown in Fig. 3, is plotted against GPM IMERG daily rainfall from July 1, 2018, to September 5, 2018.

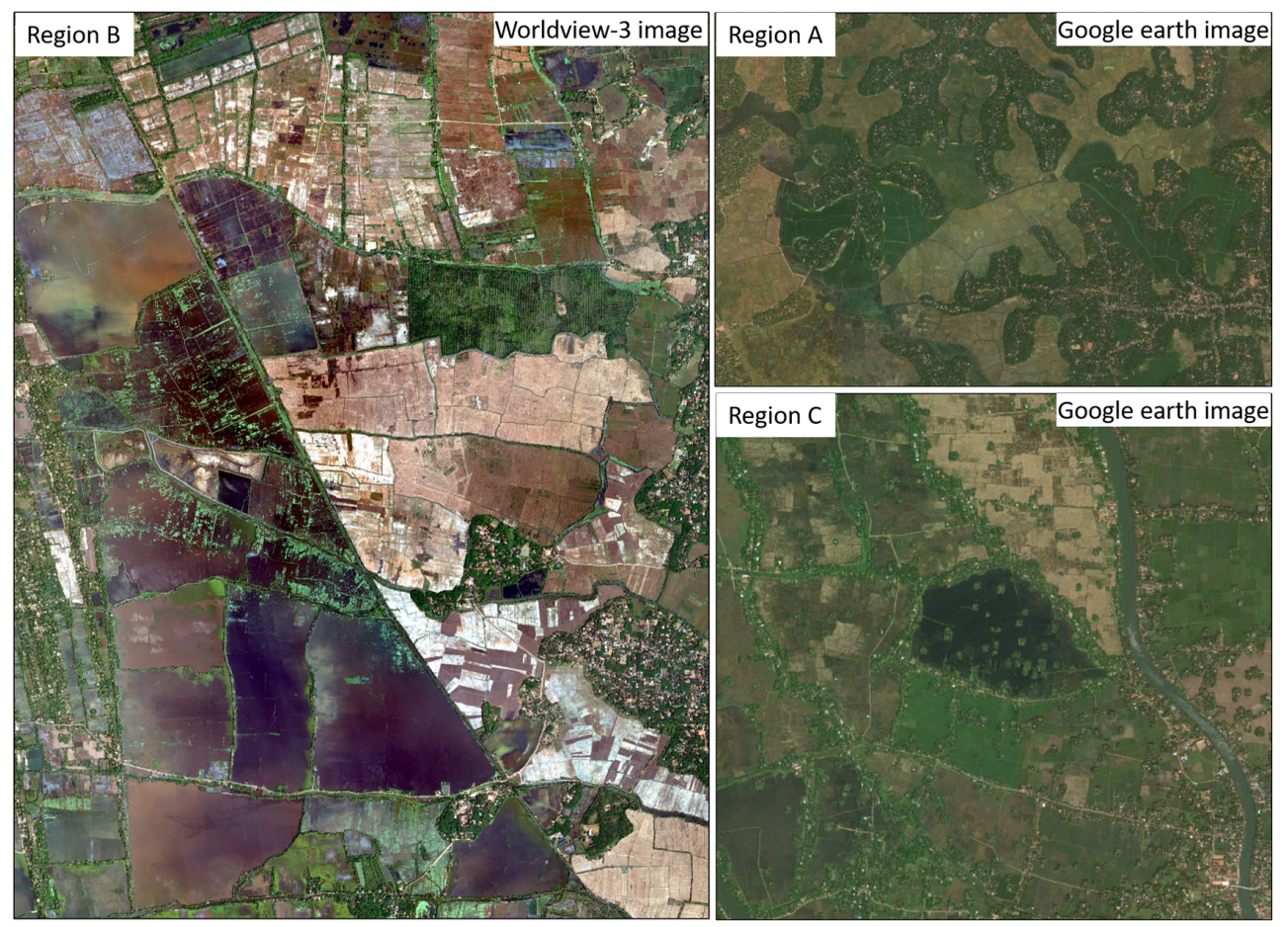

Fig. 7 Optical remote sensing images acquired before the flood event for the regions, as shown in Fig. 3. 
In the study area, SAR images acquired in July and August are used, where the crops are in a growing stage, which led to a high amount of volume scattering. From region A of Fig. 3, it is observed that the flood is predominantly detected among all the land uses except for urban areas. Many studies ${ }^{50,55,81}$ stated that the major challenges for flood mapping in urban areas are layover, shadows, and the presence of radar-like reflecting surfaces. In this study, the test site is characterized by presence of radar-like reflecting surfaces and heterogeneous built forms, which results in layover and shadows. Therefore, the automatic thresholding algorithm is applied on preflood images to extract these land surfaces that lead overestimation of flood area. After identifying the flooded areas from flood images and post-flood images, the land surfaces obtained from preflood image are masked out to avoid overestimation. Also, the increased backscatter from flooded urban streets or high-density built-up areas results in underdetection, which needs to be tackled by high-resolution SAR imagery and interferometric SAR coherence.

After the first rainfall spell occurred in the second and third weeks of July 2018 as shown in Fig. 6, the land surface got flooded in all the regions of Fig. 3, which is evident from Fig. 5. Even though the geographical area and land use of region A and B of Fig. 3 are the same, the flood area obtained from region $\mathrm{B}$ is higher than region $\mathrm{A}$. This is due to the low elevation of region $\mathrm{B}$, high rainfall, and flow of drainage water to Vembanadu Lake. As the floodwater receded, there is a decrease in flood area until the major rainfall spell occurred during the third week of August 2018. After the major rainfall spell, there is a steep increase in the flood area and a decreasing trend afterward. Among all the selected locations, the region B is profoundly affected by the flood. For the better insight of water flow dynamics at a larger spatial area, the regional level flood mapping is carried out and described in Sec. 4.2.1.

\subsubsection{District-level flood mapping}

To carry out district-level postdisaster strategic planning activities, a district-level flood damage assessment is required. Therefore, both quantitative and qualitative flood assessment are carried out in the GEE cloud platform at the district level. The reducer and quantification functions are developed in GEE to generate the spatio-temporal flood maps at the district level and to quantify the flood area, respectively. The district-wise temporal flood area obtained from GEE is shown in Fig. 8, and it is observed that Alappuzha is the worst affected, followed by Kottayam and Thrissur districts. Therefore, the flooding pattern (increasing and receding) in these three districts is studied in detail. The spatio-temporal distribution and quantitative estimation of flood area with the rainfall for these three districts are shown in Figs. 9 and 10, respectively. From Fig. 10, it is inferred that the rainfall pattern for all three districts is almost similar with an offset. The flood area derived from SAR images also follows the district-level rainfall pattern.

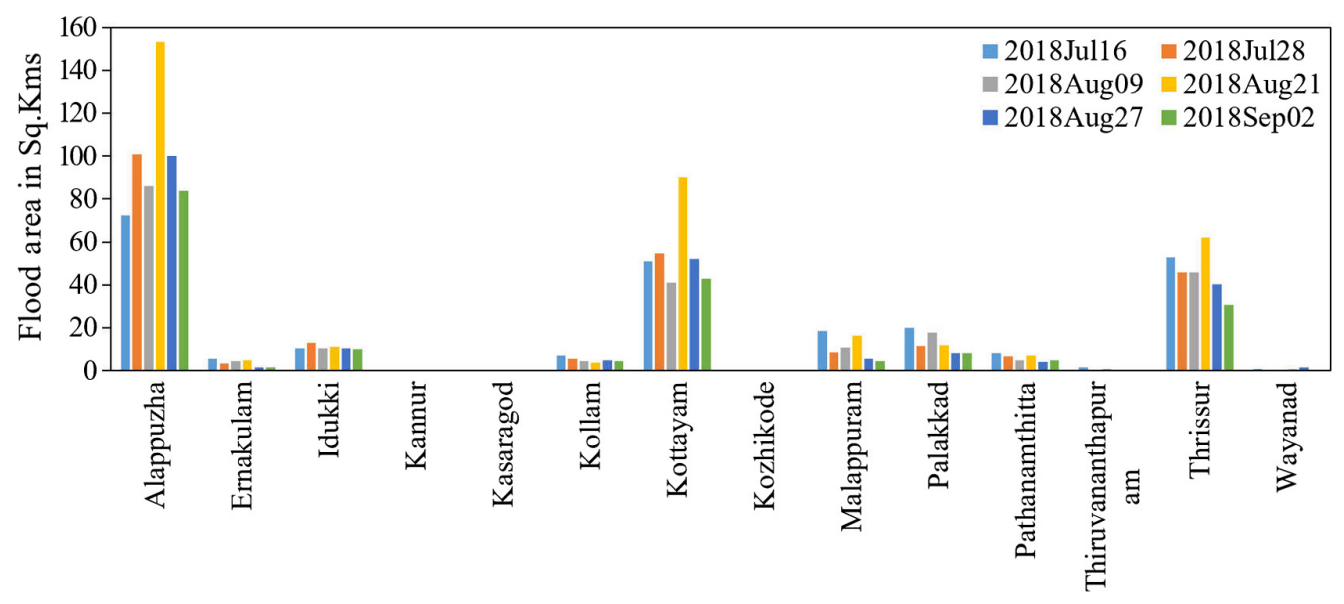

Fig. 8 District wise temporal flood area obtained from GEE for Kerala state. 


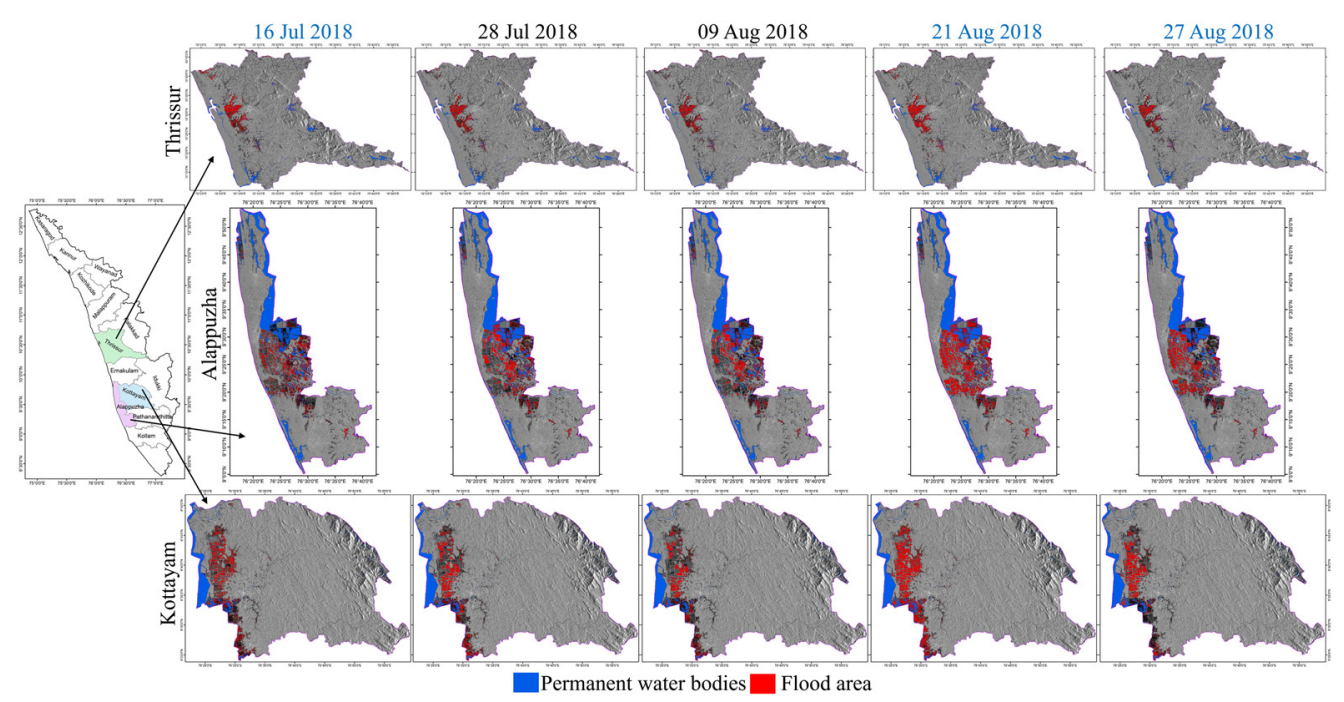

Fig. 9 Spatio-temporal distribution of flood area for Thrissur, Alappuzha, and Kottayam districts. Red and blue color represent flood and perennial water bodies, respectively. Preflood $\sigma_{0}$ image derived from Sentinel-1 is used as a background.

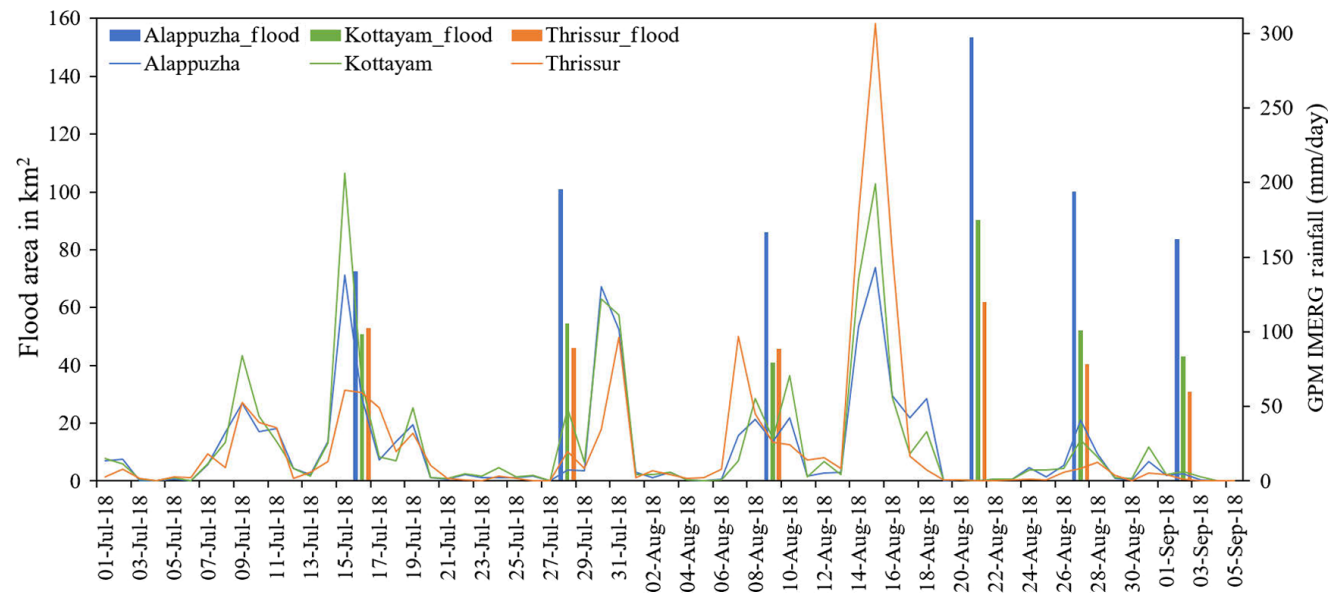

Fig. 10 Flood area obtained from three districts as shown in Fig. 9 is plotted against their respective district wise GPM IMERG daily rainfall from July 1, 2018, to September 5, 2018.

During the first spell of rainfall in July 2018, the land surface got flooded among these three districts, and the floodwater started receding. An increase in the flood area is observed for Alappuzha and Kottayam districts, whereas decreasing trend for Thrissur district is obtained for the images acquired on July 28, 2018. Subsequently, a decreasing trend of flood area is observed in all three districts for images acquired on August 9, 2018. By the time of image acquisition on August 21, 2018, the land surface got saturated. After the heavy rainfall occurred during the third week of August 2018, there is a steep increase in the flood area among these three districts and subsequently decreasing trend. Even though the rainfall received by Thrissur during the third week of August 2018 is higher than the other two districts, the flood area obtained is lesser than the other two districts. This is due to the location of Thrissur in higher elevation region as shown in Appendix 2 (Sec. 6.2), and receding of the floodwater through the drainage channels is shown in Fig. 11.

Apparently, Alappuzha has most flood-affected area due to its low elevation, backwater flow, dam water release, and the majority of the west-flowing rivers draining into Vembanadu Lake. Similarly, the state-level flood maps are generated and given in Appendix 1 (Sec. 6.1). At a district and a state level, the total time consumed for spatio-temporal flood maps generation is $\sim 2.5$ and 4 min, respectively. 


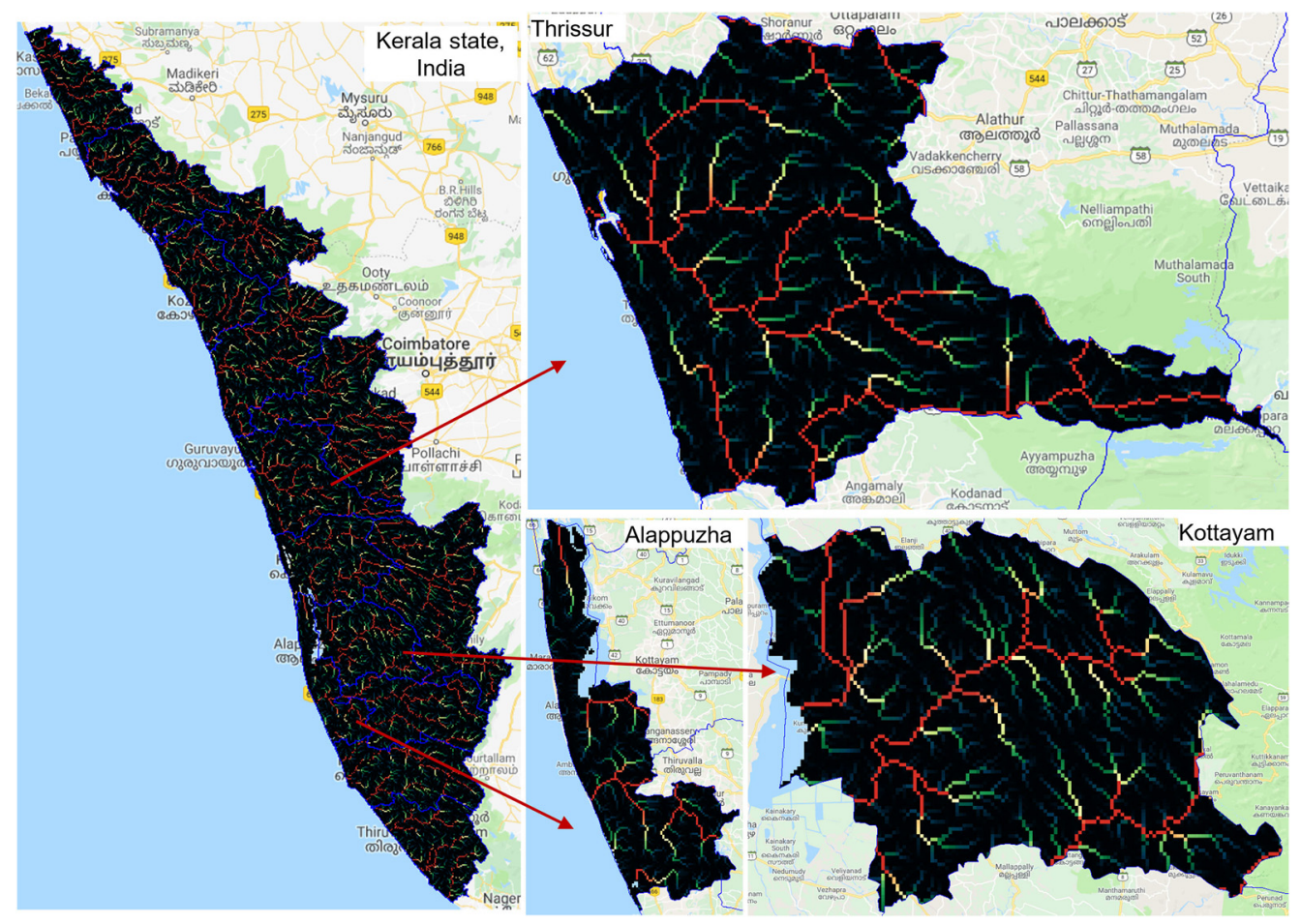

Fig. 11 Flow accumulation maps generated from GEE cloud platform for Kerala state, Thrissur, Alappuzha, and Kottayam districts, respectively.

\subsection{Validation}

The results obtained from GEE for all image acquisition dates cannot be validated due to lack of ground truth data at that particular time. Most of the ground truth data are collected after the major rainfall spell in the third week of August 2018. So, validation is carried out on the flooded area obtained from the SAR image acquired at high flood stage on August 21, 2018. The ground truth data are generated from Sentinel-2 optical images acquired on August 22, 2018, along with field survey data. The ground truth vector file generated in GEE is rasterized with the same pixel size as Sentinel- $1 \sigma_{0}$ images and the same spatial extent as region C of Fig. 3. The PWB pixels are excluded from the performance metrics calculation. As mentioned in Sec. 3.5, various performance metrics are generated, as shown in Table 2.

The TPR and TNR values are $66 \%$ and $98 \%$, respectively, which indicate that for nonflood class, the ground truth is almost matching with algorithm output, whereas some discrepancies are seen for flood class. A $100 \% \mathrm{~F}$-score value represents the perfect match between predicted flood area and ground truth flood area, i.e., perfect recall and precision for flood class, and a $0 \%$ represents a perfect mismatch. The accuracy and $F$-score values for the region $\mathrm{C}$ are $82.04 \%$ and $78.55 \%$, respectively, which show the close match with the reference data for both classes and flood class, respectively. The value of $F$-score is promising considering the usage of Otsu's automatic thresholding algorithm without any manual tuning or modification of algorithm.

Table 2 Flood mapping performance metrics for region C.

\begin{tabular}{lllll}
\hline \hline & & \multicolumn{2}{c}{ Ground truth } \\
\cline { 3 - 4 } & & Flood & Nonflood & \\
\hline Algorithm output & Flood & $\mathrm{TP}=39204$ & $\mathrm{FP}=1214$ & $\mathrm{PPV}=0.97$ \\
& Nonflood & $\mathrm{FN}=20119$ & $\mathrm{TN}=58231$ & $\mathrm{NPV}=0.74$ \\
& & $\mathrm{TPR}=0.66$ & $\mathrm{TNR}=0.98$ & \\
\hline \hline
\end{tabular}


The difference in the amount of algorithm performance for both classes (flood and nonflood) and flood class alone is quite low. Further, high-resolution SAR images and timely acquisition of validation data may boost accuracy.

\section{Conclusions}

A unified framework for flood mapping in GEE cloud platform is proposed, which utilizes multitemporal EO data. The GEE4FLOOD processing chain uses Otsu's thresholding algorithm for finding the optimum threshold for each SAR image. GEE4FLOOD is user-friendly, efficient in data processing, less time-consuming, and scalable to varying geographical extents. The main advantage is that it requires minimal user inputs such as defining the area of interest and selection of preflood and flood images. The area of interest can be either manually drawn in the GEE platform or a shapefile has to be imported. Therefore, GEE4FLOOD can be utilized by policymakers, disaster management personnel, urban planners, and civilians irrespective of their knowledge about EO data. GEE4FLOOD is implemented on 2018 flood event of Kerala state to understand the flood progression and receding pattern. The flood maps generated from GEE4FLOOD show an acceptable agreement with IMERG rainfall data and other secondary reports. An overall accuracy of $82 \%$ for both (flood and nonflood) classes and $78.5 \%$ accuracy for flood class alone is achieved. It is interesting to look into the processing time of the proposed framework. The time taken for generating the spatio-temporal flood maps is $\sim 2$ to 4 min for varying geographical extent (district to state level).

Apart from the Kerala flood event, the processing chain can be equally addressed for any other flood event. It is advisable to consider a couple of points while implementing the GEE4FLOOD. (1) A cloud-free preflood image needs to be selected as it contributes to the reduction of flood area overestimation. (2) In case of unavailability of SAR images during heavy rainfall, users need to wisely choose the nearest available SAR images in the span of flood duration. (3) It is suggested to collect the ground truth data at the time of SAR image acquisition if possible or immediately after the rainfall. (4) In high-density urban areas, flood mapping with GRD products available with GEE catalog may not yield desirable accuracy. With the additional use of input parameters like VH pol image data, coherence information obtained by SLC data processing may enhance the flood area estimation, which can be studied in the future. In addition, validation dataset derived from crowd sourcing might also be explored. Nonetheless, GEE4FLOOD has shown promising results in case the of 2018 flood event of Kerala state, India. As GEE4FLOOD is universally applicable, it can be used for effective decision-making process in a comprehensive disaster management cycle.

\section{Appendix: GEE Performance}

Table 3 shows the computational time and memory usage for generating the flood maps in GEE high-performance computing cloud platform.

\subsection{State-Level Flood Mapping}

The spatio-temporal flood maps generated in GEE cloud platform are shown in Fig. 12. From the figure it is observed that on September 2, 2018, the flood is receded and the land surface regained its original state.

\subsection{Elevation}

The HydroSHEDS hydrologically conditioned DEM available in GEE cloud platform with 3 arc sec spatial resolution is fetched and clipped to three districts as shown in Fig. 2. The elevation values for Thrissur, Alappuzha, and Kottayam are ranging from -18 to 1361, -27 to 107, and -29 to $1155 \mathrm{~m}$, respectively (Fig. 13). While generating the flood maps at a regional scale, i.e., district or a state level, it is imperative that masking out higher elevation regions may optimize the computational time. Here, in this study, the higher slopes were masked out in GEE while 
Vanama, Mandal and Rao: GEE4FLOOD: rapid mapping of flood areas...

Table 3 Algorithm performance and computational time for flood mapping in GEE.

\begin{tabular}{|c|c|c|c|}
\hline Compute & Peak mem & Count & Description \\
\hline 20379.613 & $162 \mathrm{M}$ & 7344 & Algorithm Image.reduceNeighborhood computing pixels \\
\hline 3438.917 & $101 \mathrm{M}$ & $9,899,720$ & (plumbing) \\
\hline 1939.475 & $927 \mathrm{M}$ & 49,342 & Algorithm Image.log10 computing pixels \\
\hline 1936.756 & $27 \mathrm{M}$ & 1632 & Algorithm Image.reduce computing pixels \\
\hline 1669.345 & $1.2 \mathrm{M}$ & 120 & Algorithm ImageCollection.reduce with reducer Reducer.median \\
\hline 1422.789 & $741 \mathrm{M}$ & 408 & Algorithm Image.arrayReduce computing pixels \\
\hline 1086.665 & $25 \mathrm{M}$ & 48,934 & Algorithm Image.load computing pixels \\
\hline 483.94 & $92 \mathrm{M}$ & 728,281 & No description available \\
\hline 475.196 & $5.7 \mathrm{M}$ & 167,710 & Loading assets: COPERNICUS/S1_GRD_FLOAT/(...) \\
\hline 467.518 & $7.6 \mathrm{M}$ & 15,993 & Algorithm (user-defined function) \\
\hline 456.028 & 8.0M & 57,502 & Algorithm Image.multiply computing pixels \\
\hline 240.907 & $36 \mathrm{M}$ & 1632 & Algorithm Image.abs computing pixels \\
\hline 163.687 & $10 \mathrm{M}$ & 763,464 & Algorithm ImageCollection.mosaic \\
\hline 106.021 & $9.1 \mathrm{M}$ & 408 & Algorithm Image.pow computing pixels \\
\hline 100.481 & $16 \mathrm{M}$ & 6648 & Reprojection precalculation between EPSG:32643 and EPSG:4326 \\
\hline 47.3 & $27 \mathrm{k}$ & 729,090 & Algorithm Image.clip \\
\hline 44.791 & $3.8 \mathrm{M}$ & 661,717 & Algorithm Image.select \\
\hline 41.187 & $1.0 \mathrm{M}$ & 950,070 & Algorithm Image.resample \\
\hline 26.887 & $21 \mathrm{M}$ & 549,298 & Loading assets: COPERNICUS/S1_GRD_FLOAT \\
\hline 25.956 & $414 \mathrm{k}$ & 604,800 & Algorithm PointMatcher.PointMatcherContainer \\
\hline 14.611 & $1.4 \mathrm{M}$ & 223,485 & Algorithm Image.log10 \\
\hline 14.134 & $19 \mathrm{k}$ & 393,600 & Algorithm Image.constant \\
\hline 12.596 & $5.3 \mathrm{M}$ & 1012 & Algorithm Image.reduceRegion \\
\hline 11.751 & $4.0 \mathrm{M}$ & 516,091 & Loading assets: COPERNICUS/S1_GRD \\
\hline 7.195 & 584 & 48,934 & Reprojecting pixels from EPSG:32643 to EPSG:4326 \\
\hline 6.585 & $1.0 \mathrm{M}$ & 27,936 & Algorithm Image.clip computing pixels \\
\hline 4.75 & $1.9 \mathrm{M}$ & 241,914 & Algorithm Image.addBands \\
\hline 3.536 & $100 \mathrm{k}$ & 11,316 & Reprojecting geometry to EPSG: 4326 \\
\hline 3.531 & $983 \mathrm{k}$ & 81 & Encoding pixels to image \\
\hline 2.812 & $1.3 \mathrm{M}$ & 232,305 & Algorithm Image.multiply \\
\hline 1.708 & $35 \mathrm{k}$ & 1130 & Algorithm Image.displacement \\
\hline 1.019 & $537 \mathrm{k}$ & 196 & Table query \\
\hline 0.988 & $2.8 \mathrm{k}$ & 248,640 & Algorithm Image.resample computing pixels \\
\hline 0.988 & 800 & 17,484 & Algorithm Image.constant computing pixels \\
\hline 0.775 & $337 \mathrm{k}$ & 162 & Reprojecting geometry to SR-ORG:6627 \\
\hline 0.686 & $418 \mathrm{k}$ & 216 & Algorithm Image.paint computing pixels \\
\hline 0.408 & $39 k$ & 13,230 & Algorithm Image.reduceNeighborhood \\
\hline 0.299 & $162 \mathrm{k}$ & 196 & Table decode \\
\hline 0.293 & 648 & 9792 & Algorithm Image.updateMask computing pixels \\
\hline 0.281 & $7.2 \mathrm{k}$ & 196 & Table metadata \\
\hline 0.273 & 760 & 7344 & Algorithm Image.neighborhoodToBands computing pixels \\
\hline
\end{tabular}


Vanama, Mandal and Rao: GEE4FLOOD: rapid mapping of flood areas...

Table 3 (Continued).

\begin{tabular}{lccl}
\hline \hline \multicolumn{2}{c}{ Viewing 121 profiles, 40 from application programming interface (API) calls, and 81 from map tiles. } \\
\hline Compute & Peak mem & Count & \multicolumn{1}{c}{ Description } \\
\hline 0.272 & $60 \mathrm{k}$ & 125,22 & Algorithm Image.updateMask \\
0.218 & $50 \mathrm{k}$ & 1470 & Algorithm Image.neighborhoodToBands \\
0.209 & $1.6 \mathrm{k}$ & 4896 & Algorithm Image.eq computing pixels \\
0.198 & $26 \mathrm{M}$ & 3528 & Algorithm Image.displacement computing pixels \\
0.194 & $1.6 \mathrm{k}$ & 5712 & Algorithm Image.subtract computing pixels \\
0.183 & $23 \mathrm{k}$ & 10,290 & Algorithm Image.subtract \\
0.172 & $1.8 \mathrm{k}$ & 4896 & Algorithm Image.divide computing pixels \\
0.138 & $7.5 \mathrm{k}$ & 1172 & Algorithm Image.displace \\
0.113 & $12 \mathrm{k}$ & 141 & Listing collection \\
\hline
\end{tabular}
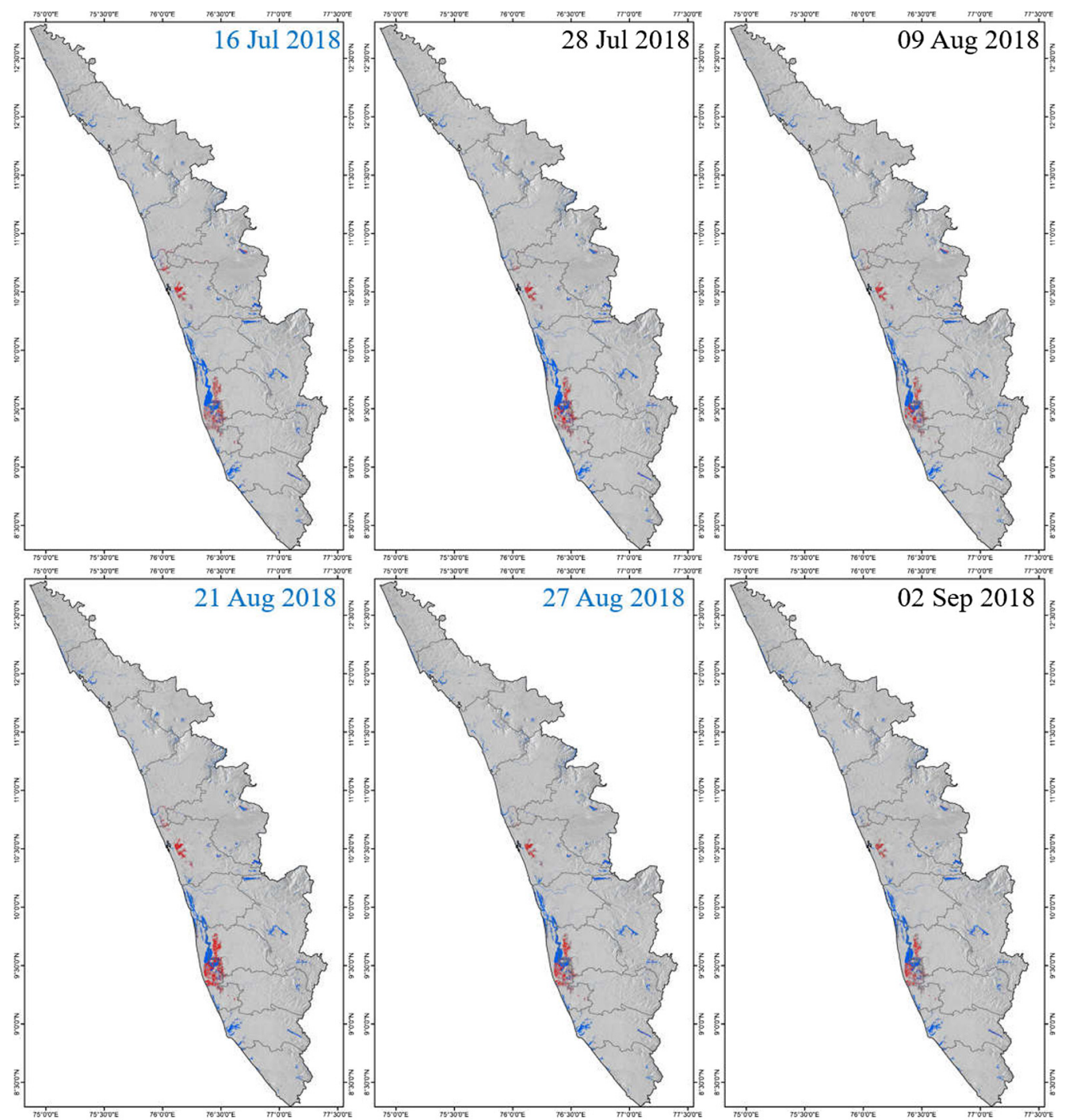

Permanent water bodies

Flood area

Fig. 12 State-level spatio-temporal flood maps for 2018 flood event of Kerala state, India. 

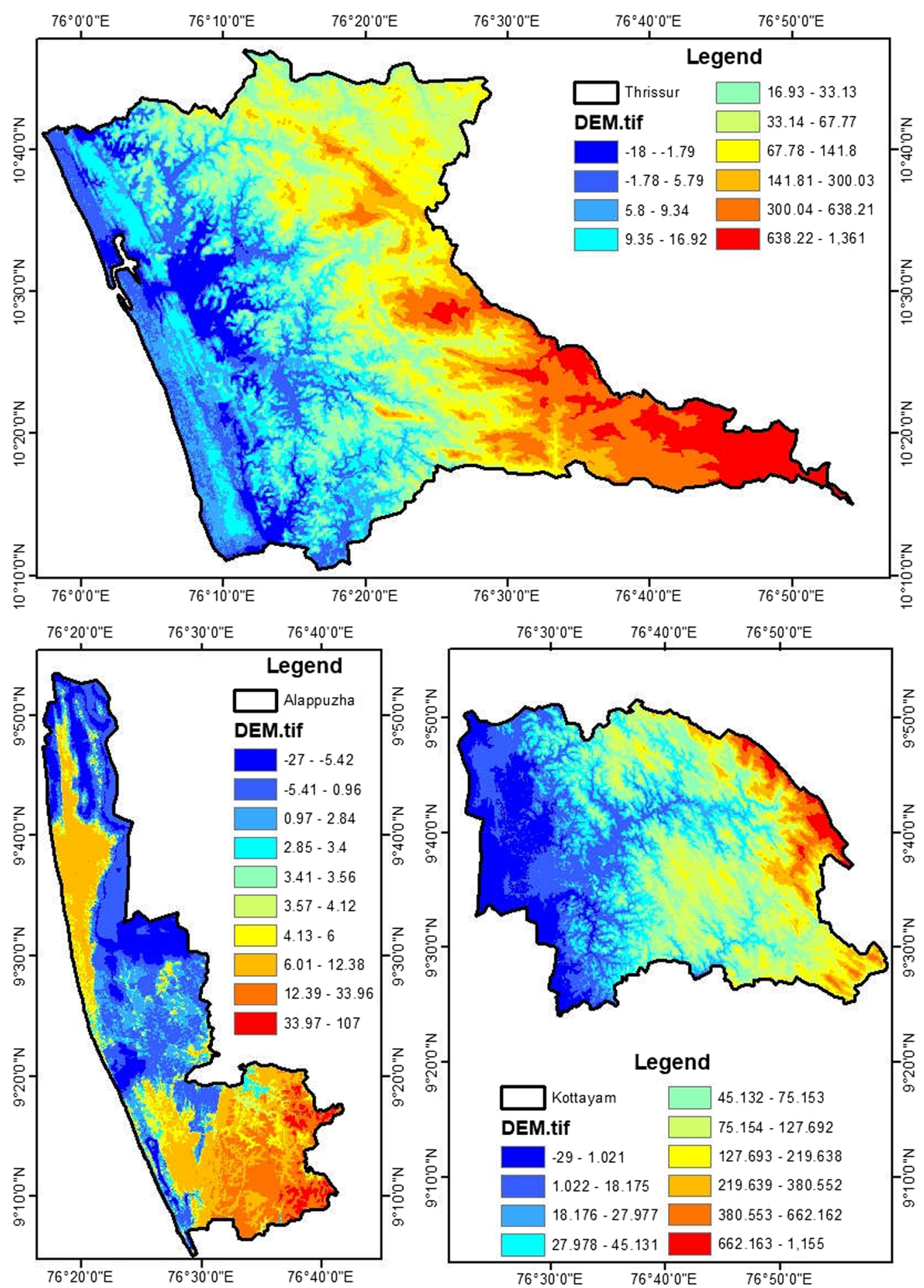

Fig. 13 Elevation map for Thrissur, Alappuzha, and Kottayam districts of Kerala state, India.

computing the flood area at state and district level. This is achieved by fetching the HydroDEM into GEE from terrain information obtained using .Terrain() operator. The slope image was fetched from terrain dataset using . select() operator.

\section{Acknowledgments}

The authors would like to thank Canalpy, Tata Institute of Social Sciences, Mumbai, for sharing the field data. The authors would also like to thank DigitalGlobe for providing the 
high-resolution WorldView-3 images and ESA for providing Sentinel-1 through Copernicus Open Access Hub. The first author is thankful to the Ministry of Human Resource Development, Government of India for providing necessary computational facilities through the project funding (Grant No. 14MHRD005). No potential conflicts of interest were reported by the authors.

\section{References}

1. X. Huang et al., "Flood hazard in Hunan province of China: an economic loss analysis," Nat. Hazards 47(1), 65-73 (2008).

2. NDMA-India, "National disaster management guidelines-management of floods," Tech. Rep., Publication of National Disaster Management Authority (NDMA), Government of India, pp. 1-135 (2008).

3. R. Dhiman et al., "Flood risk and adaptation in Indian coastal cities: recent scenarios," Appl. Water Sci. 9(1), 5 (2019).

4. T. Ologunorisa and M. Abawua, "Flood risk assessment: a review," J. Appl. Sci. Environ. Manage. 9(1), 57-63 (2005).

5. S. Panhalkar and A. P. Jarag, "Flood risk assessment of Panchganga River (Kolhapur district, Maharashtra) using GIS-based multicriteria decision technique," Curr. Sci. 112(4), 785-793 (2017).

6. P. Matgen et al., "Towards an automated SAR-based flood monitoring system: lessons learned from two case studies," Phys. Chem. Earth Parts A/B/C 36(7-8), 241-252 (2011).

7. G. Schumann et al., "Assisting flood disaster response with earth observation data and products: a critical assessment," Remote Sens. 10(8), 1230 (2018).

8. A. Domeneghetti, G. J.-P. Schumann, and A. Tarpanelli, "Preface: remote sensing for flood mapping and monitoring of flood dynamics," Remote Sens. 11(8), 943 (2019).

9. W. Wagner, "Big data infrastructures for processing sentinel data," in Photogrammetric Week,D. Fritsch, Ed., Vol. 15, pp. 93-104 (2015).

10. A. Bucur et al., "Development of an Earth observation cloud platform in support to water resources monitoring," in Earth Observation Open Science and Innovation, P. P. Mathieu and C. Aubrecht, Eds., pp. 275-283, Springer, Cham (2018).

11. G. J. Schumann et al., Global Flood Hazard: Applications in Modeling, Mapping, and Forecasting, Vol. 233, John Wiley \& Sons, American Geophysical Union (2018).

12. G. J.-P. Schumann and D. K. Moller, "Microwave remote sensing of flood inundation," Phys. Chem. Earth Parts A/B/C 83, 84-95 (2015).

13. D. Werle, T. C. Martin, and K. Hasan, "Flood and coastal zone monitoring in Bangladesh with Radarsat ScanSAR: technical experience and institutional challenges," Johns Hopkins APL Tech. Dig. 21(1), 148-154 (2000).

14. F. Bonn and R. Dixon, "Monitoring flood extent and forecasting excess runoff risk with RADARSAT-1 data," Nat. Hazards 35(3), 377-393 (2005).

15. L. M. Kiage et al., "Applications of Radarsat-1 synthetic aperture radar imagery to assess hurricane-related flooding of coastal Louisiana," Int. J. Remote Sens. 26(24), 5359-5380 (2005).

16. A. M. Dewan and K. Kankam-Yeboah, "Using synthetic aperture radar (SAR) data for mapping river water flooding in an urban landscape: a case study of Greater Dhaka, Bangladesh,” J. Jpn. Soc. Hydrol. Water Resour. 19(1), 44-54 (2006).

17. S. Martinis, "A Sentinel-1 times series-based exclusion layer for improved flood mapping in arid areas," in IEEE Int. Geosci. and Remote Sens. Symp., IEEE, pp. 6584-6587 (2018).

18. B. Tavus et al., "Considerations on the use of Sentinel-1 data in flood mapping in urban areas: Ankara (Turkey) 2018 floods," Int. Arch. Photogramm. Remote Sens. Spat. Inf. Sci. XLII-5, 575-581 (2018).

19. M.-J. Jo et al., "Flood extent mapping using dual-polarimetric Sentinel-1 synthetic aperture radar imagery," Int. Arch. Photogramm. Remote Sens. Spat. Inf. Sci. 42(3), 711-713 (2018).

20. R. Manavalan, "SAR image analysis techniques for flood area mapping-literature survey," Earth Sci. Inf. 10(1), 1-14 (2017). 
21. J.-B. Henry et al., "Envisat multi-polarized ASAR data for flood mapping," Int. J. Remote Sens. 27(10), 1921-1929 (2006).

22. M. Gong, Y. Cao, and Q. Wu, "A neighborhood-based ratio approach for change detection in SAR images," IEEE Geosci. Remote Sens. Lett. 9(2), 307-311 (2012).

23. T. Celik, "Change detection in satellite images using a genetic algorithm approach," IEEE Geosci. Remote Sens. Lett. 7(2), 386-390 (2010).

24. S. Long, T. E. Fatoyinbo, and F. Policelli, "Flood extent mapping for Namibia using change detection and thresholding with SAR," Environ. Res. Lett. 9(3), 035002 (2014).

25. J. Lim and K.-S. Lee, "Flood mapping using multi-source remotely sensed data and logistic regression in the heterogeneous mountainous regions in North Korea," Remote Sens. 10(7), 1036 (2018).

26. G. Nico et al., "Comparison of SAR amplitude vs. coherence flood detection methods-a GIS application,” Int. J. Remote Sens. 21(8), 1619-1631 (2000).

27. F. Yulianto et al., "Detecting areas affected by flood using multi-temporal ALOS PALSAR remotely sensed data in Karawang, West Java, Indonesia," Nat. Hazards 77(2), 959-985 (2015).

28. S. Mahdavi et al., "A PolSAR change detection index based on neighborhood information for flood mapping," Remote Sens. 11(16), 1854 (2019).

29. X. Sun et al., "Soft urban water cover extraction using mixed training samples and support vector machines," Int. J. Remote Sens. 36(13), 3331-3344 (2015).

30. S. Skakun, "A neural network approach to flood mapping using satellite imagery," Comput. Inf. 29(6), 1013-1024 (2012).

31. L. Pulvirenti et al., "An algorithm for operational flood mapping from synthetic aperture radar (SAR) data based on the fuzzy logic," Nat. Hazard Earth Syst. Sci. nhess-11, 529-540 (2011).

32. S. Martinis and C. Rieke, "Backscatter analysis using multi-temporal and multi-frequency SAR data in the context of flood mapping at River Saale, Germany," Remote Sens. 7(6), 7732-7752 (2015).

33. D. Amitrano et al., "Unsupervised rapid flood mapping using Sentinel-1 GRD SAR images," IEEE Trans. Geosci. Remote Sens. 56(6), 3290-3299 (2018).

34. G. Mallinis et al., "An object-based approach for flood area delineation in a transboundary area using ENVISAT ASAR and LANDSAT TM data," Int. J. Digital Earth 6(Suppl. 2), 124-136 (2013).

35. X. Shen et al., "Inundation extent mapping by synthetic aperture radar: a review," Remote Sens. 11(7), 879 (2019).

36. G. Di Baldassarre et al., "Flood-plain mapping: a critical discussion of deterministic and probabilistic approaches," Hydrol. Sci. J. 55(3), 364-376 (2010).

37. S. Martinis, A. Twele, and S. Voigt, "Towards operational near real-time flood detection using a split-based automatic thresholding procedure on high resolution TerraSAR-X data," Nat. Hazards Earth Syst. Sci. 9(2), 303-314 (2009).

38. S. Martinis, A. Twele, and S. Voigt, "Unsupervised extraction of flood-induced backscatter changes in SAR data using Markov image modeling on irregular graphs," IEEE Trans. Geosci. Remote Sens. 49(1), 251-263 (2011).

39. L. Giustarini et al., "A change detection approach to flood mapping in urban areas using TerraSAR-X," IEEE Trans. Geosci. Remote Sens. 51(4), 2417-2430 (2013).

40. A. Benoudjit and R. Guida, "A novel fully automated mapping of the flood extent on SAR images using a supervised classifier," Remote Sens. 11(7), 779 (2019).

41. D. Mason et al., "Automatic near real-time selection of flood water levels from high resolution synthetic aperture radar images for assimilation into hydraulic models: a case study," Remote Sens. Environ. 124, 705-716 (2012).

42. S. Kundu et al., "Flood monitoring using microwave remote sensing in a part of Nuna river basin, Odisha, India," Nat. Hazards 76(1), 123-138 (2015).

43. N. Otsu, "A threshold selection method from gray-level histograms," IEEE Trans. Syst. Man Cybern. 9(1), 62-66 (1979).

44. J. Kittler and J. Illingworth, "Minimum error thresholding," Pattern Recognit. 19(1), 41-47 (1986). 
45. J. N. Kapur, P. K. Sahoo, and A. K. Wong, "A new method for gray-level picture thresholding using the entropy of the histogram," Comput. Vision Graphics Image Process. 29(3), 273-285 (1985).

46. D.-M. Tsai, "A fast thresholding selection procedure for multimodal and unimodal histograms," Pattern Recognit. Lett. 16(6), 653-666 (1995).

47. D. C. Mason et al., "Improving river flood extent delineation from synthetic aperture radar using airborne laser altimetry," IEEE Trans. Geosci. Remote Sens. 45(12), 3932-3943 (2007).

48. P. Matgen et al., "Integration of SAR-derived river inundation areas, high-precision topographic data and a river flow model toward near real-time flood management," Int. J. Appl. Earth Obs. Geoinf. 9(3), 247-263 (2007).

49. P. Manjusree et al., "Optimization of threshold ranges for rapid flood inundation mapping by evaluating backscatter profiles of high incidence angle SAR images," Int. J. Disaster Risk Sci. 3(2), 113-122 (2012).

50. L. Landuyt et al., "Flood mapping based on synthetic aperture radar: an assessment of established approaches," IEEE Trans. Geosci. Remote Sens. 57(2), 722-739 (2019).

51. A. Dasgupta et al., "Towards operational SAR-based flood mapping using neuro-fuzzy texture-based approaches," Remote Sens. Environ. 215, 313-329 (2018).

52. S. Martinis et al., "Comparing four operational SAR-based water and flood detection approaches," Int. J. Remote Sens. 36(13), 3519-3543 (2015).

53. Luxembourg Institute of Science and Technology, "Hasard mapping algorithm implemented on the European Space Agency's (ESA) grid processing on demand (GPOD)" (2017).

54. M. Chini et al., "SAR coherence and polarimetric information for improving flood mapping," in IEEE Int. Geosci. and Remote Sens. Symp., IEEE, pp. 7577-7580 (2016).

55. M. Chini et al., "A hierarchical split-based approach for parametric thresholding of SAR images: flood inundation as a test case," IEEE Trans. Geosci. Remote Sens. 55(12), 6975-6988 (2017).

56. M. Chini et al., "Sentinel-1 INSAR coherence to detect floodwater in urban areas: Houston and Hurricane Harvey as a test case," Remote Sens. 11(2), 107 (2019).

57. N. Gorelick et al., "Google Earth Engine: planetary-scale geospatial analysis for everyone," Remote Sens. Environ. 202, 18-27 (2017).

58. L. Kumar and O. Mutanga, "Google Earth Engine applications since inception: usage, trends, and potential," Remote Sens. 10(10), 1509 (2018).

59. D. Mandal et al., "Sen4rice: a processing chain for differentiating early and late transplanted rice using time-series Sentinel-1 SAR data with Google Earth Engine," IEEE Geosci. Remote Sens. Lett. 15(12), 1947-1951 (2018).

60. X. Liu et al., "High-resolution multi-temporal mapping of global urban land using Landsat images based on the Google Earth Engine platform," Remote Sens. Environ. 209, 227-239 (2018).

61. N. Sidhu, E. Pebesma, and G. Câmara, "Using Google Earth Engine to detect land cover change: Singapore as a use case," Eur. J. Remote Sens. 51(1), 486-500 (2018).

62. N. N. Patel et al., "Multitemporal settlement and population mapping from Landsat using Google Earth Engine," Int. J. Appl. Earth Obs. Geoinf. 35, 199-208 (2015).

63. M. C. Hansen et al., "High-resolution global maps of 21st-century forest cover change," Science 342(6160), 850-853 (2013).

64. D. Hammer, R. Kraft, and D. Wheeler, "Forma: forest monitoring for action-rapid identification of pan-tropical deforestation using moderate-resolution remotely sensed data," Center for Global Development Working Paper (192) (2009).

65. J.-F. Pekel et al., "High-resolution mapping of global surface water and its long-term changes," Nature 540(7633), 418-422 (2016).

66. K. Uddin, M. A. Matin, and F. J. Meyer, "Operational flood mapping using multi-temporal Sentinel-1 SAR images: a case study from Bangladesh," Remote Sens. 11(13), 1581 (2019).

67. H. A. Zurqani et al., "Geospatial analysis of land use change in the Savannah River basin using Google Earth Engine," Int. J. Appl. Earth Obs. Geoinf. 69, 175-185 (2018).

68. S. Sánchez-Ruiz et al., "Growing stock volume from multi-temporal Landsat imagery through Google Earth Engine," Int. J. Appl. Earth Obs. Geoinf. 83, 101913 (2019). 
69. Kerala Forest Department, "Kerala at a glance," http://www.forest.kerala.gov.in/index.php/ forest/kerala-state-profile (2018).

70. Indian Meteorological Department, "Performance of south west monsoon 2018 over Kerala," Tech. Rep., Meteorological Centre, Thiruvananthapuram (2018).

71. I. Central Water Commission, "Study report: Kerala flood of August 2018," Tech. Rep., Government of India, Central Water Commission, Hydrological Studies Organisation (2018).

72. M. Behera, "Kerala floods joint detailed needs assessment report," Tech. Rep., Sphere India, National Coalition of Humanitarian Agencies in India (2008).

73. Google Earth Engine API, "Sentinel-1 algorithms," https://developers.google.com/earthengine/sentinel1 (2018).

74. DigitalGlobe, "Open data program-flooding in India," https://www.digitalglobe.com/ opendata/flooding-in-india/pre-event (2018).

75. Google Earth Engine, "Google Earth Engine catalog," https://developers.google.com/earthengine/datasets/ (2019).

76. S. Hong et al., "Water area extraction using RADARSAT SAR imagery combined with landsat imagery and terrain information," Sensors 15(3), 6652-6667 (2015).

77. J. Li and S. Wang, "An automatic method for mapping inland surface waterbodies with Radarsat-2 imagery," Int. J. Remote Sens. 36(5), 1367-1384 (2015).

78. T. Erickson, "Sentinel-1 data ingestion latency time in GEE," https://colab.research.google .com/drive/1zLWBKIDF-YU3txsZd7Hk2WIdM4ebmK4s (2017).

79. V. Sivaram, "Floods in Kerala," https://in.reuters.com/news/picture/floods-in-keralaidINRTS1XFOF (2018).

80. M. Tuba, "Multilevel image thresholding by nature-inspired algorithms: a short review," Comput. Sci. J. Moldova 22(3), 318-338 (2014).

81. L. Giustarini et al., "A change detection approach to flood mapping in urban areas using TerraSAR-X," IEEE Trans. Geosci. Remote Sens. 51(4), 2417-2430 (2013).

Venkata Sai Krishna Vanama received his MTech degree in Remote Sensing and GIS from Indian Institute of Remote Sensing and Andhra University (AU) in 2014. He received his BTech degree in Planning from School of Planning and Architecture, JNAFAU, Hyderabad, India, in 2012. He is currently pursing PhD in CUSE, Indian Institute of Technology Bombay, Mumbai, India. His research interest includes application of Earth Observation data for urban flood mapping and urban expansion mapping.

Dipankar Mandal is currently working toward MTech and $\mathrm{PhD}$ dual degree in Geoinformatics in CSRE, Indian Institute of Technology Bombay. He has received the Shastri Research Student Fellowship 2018 award by the Shastri Indo-Canadian Institute, India, and has been a visiting researcher at Carleton University, and Agriculture and Agri-Food, Ottawa, Canada. His research interest includes applications of SAR polarimetry for crop classification and vegetation biophysical parameter estimation.

Yalamanchili Subrahmanyeswara Rao received his $\mathrm{PhD}$ in passive microwave remote sensing of soil moisture from the Indian Institute of Technology (IIT) Bombay, Mumbai, India, in 1992. $\mathrm{He}$ is currently a professor in the Centre of Studies Resources Engineering, IIT Bombay, since 2014. His current research interests include passive and active microwave remote sensing for several applications viz. soil moisture, crop monitoring, flood mapping and SAR interferometry for DEM and displacement map generation. 